\title{
CABO DE HORNOS: UN CRISOL BIOGEOGRÁFICO EN LA CUMBRE AUSTRAL DE AMÉRICA
}

RICARDO ROZZIa,b

\section{RESUMEN}

En este trabajo se propone distinguir tres descubrimientos de Cabo de Hornos. Un primer descubrimiento habría ocurrido hace unos 7500 años, cuando los antepasados del pueblo originario yagán arribaron a los archipiélagos ubicados al sur de Tierra del Fuego. Un segundo descubrimiento tuvo lugar en 1616, cuando exploradores holandeses avistaron el Cabo de Hornos y transformaron el paradigma de la cartografía europea del siglo XVII que representaba a Tierra del Fuego adosada al continente antártico. Un tercer descubrimiento ocurrió el 2005, cuando UNESCO creó la Reserva de la Biosfera Cabo de Hornos $(\mathrm{RBCH})$ a partir del hallazgo de una excepcional riqueza de especies de briofitas (musgos y hepáticas) y líquenes que transformaron al extremo sur de América en un centro mundial de biodiversidad. En este trabajo se presenta un atributo especial de la biodiversidad de la $\mathrm{RBCH}$ : sus múltiples relaciones biogeográficas. Existen afinidades con biotas de seis regiones biogeográficas contrastantes: antárticas, bipolares (subárticas y subantárticas), circumantárticas, gondwánicas, neotropicales y altoandinas, además del alto grado de endemismo. La aproximación metodológica de la filosofía ambiental de campo tratada en el segundo grupo de artículos de este número especial de Magallania contribuye tanto al conocimiento como a la conservación de la pequeña flora de briofitas y líquenes y otras biotas que han permanecido menos percibidas y valoradas en Cabo de Hornos y otras regiones del mundo.

PALABRAS CLAVE: biogeografía, briofitas, endemismo, líquenes, subantártico.

\section{CAPE HORN: A BIOGEOGRAPHIC MELTING POT AT THE SOUTHERN END OF THE AMERICAS}

\footnotetext{
ABSTRACT

In this work, I propose to distinguish three discoveries of Cape Horn. A first discovery would have occurred about 7500 years ago, when the ancestors of the Yahgan people arrived to the archipelagos

a Parque Etnobotánico Omora, Instituto de Ecología y Biodiversidad (IEB-Chile) y Universidad de Magallanes. Puerto Williams, Provincia Antártica Chilena, Chile. $\triangle$ Ricardo.Rozzi@Unt.edu

b Sub-Antarctic Biocultural Conservation Program, Department of Philosophy and Religion \& Department of Biological Sciences, University of North Texas, 1704 West Mulberry, Denton, TX 76201, USA.
} 
located south of Tierra del Fuego. A second discovery took place in 1616, when Dutch explorers spotted Cape Horn and transformed the paradigm of the seventeenth century European cartography that represented Tierra del Fuego attached to the Antarctic Continent. A third discovery occurred in 2005, when UNESCO created the Cabo Cape Horn Biosphere Reserve ( $\mathrm{RBCH})$, based on the discovery of an exceptional richness of bryophytes (mosses and liverworts) and lichens. This finding transformed the southern end of the Americas into a world center of biodiversity for these groups of organisms. I present a special attribute of Cape Horn's biodiversity: its multiple biogeographical relationships. For Cape Horn's biodiversity, affinities can be identified with biota from six contrasting biogeographic regions: Antarctic, bipolar (subarctic and sub-Antarctic), circumantarctic, Gondwana, Neotropical and high Andean, also considering the high degree of endemism. The field environmental philosophy methodological approach (presented in the second group of articles of this special issue of Magallania) contributes both to knowledge and conservation of the small flora of bryophytes and lichens, and other biota that have remained less perceived and valued in Cape Horn and other regions of the world.

KEY WORDS: biogeography, bryophytes, endemism, lichens, subantarctic.

\section{CABO DE HORNOS: CUMBRE AUSTRAL DE AMÉRICA}

Así como el Monte Everest emerge como la cumbre de mayor altitud en el mundo, el Cabo de Hornos emerge como la cumbre austral del Continente Americano (Fig. 1). Cabo de Hornos alberga también los bosques de mayor latitud en el Hemisferio Sur. Por su posición altitudinal o latitudinal, ambas cumbres, el Everest y Cabo de Hornos, están sujetas a condiciones climáticas únicas y extremas, un atributo que adquiere la mayor relevancia cuando confrontamos un cambio climático global.

Con esta afirmación iniciamos el documento presentado ante la UNESCO para crear la Reserva de la Biosfera Cabo de Hornos (RBCH) (Rozzi et al. 2006a, 2006b, 2007). La nominación de la UNESCO se concretó el año 2005 y representó un re-descubrimiento de Cabo de Hornos (Fig. 2). Metafórica e históricamente proponemos distinguir tres descubrimientos de este hito geográfico. Por un lado, esta propuesta contribuye a superar el eurocentrismo implíito en el acto de señalar la fecha del descubrimiento de Cabo de Hornos con la llegada de un explorador holandés en 1616; esto es, varios miles de años después del arribo de los pueblos originarios al extremo austral de Sudamérica. Por otro lado, contribuye a superar un antropocentrismo que ha centrado la historia del Cabo de Hornos en los sucesos humanos; se incorpora ahora una atención por los seres humanos y el conjunto de los seres vivos. A partir del propuesto tercer descubrimiento del Cabo de Hornos, este artículo procura contribuir a visibilizar y valorizar atributos de esta "cumbre austral de América" que habían quedado omitidos por la ciencia y la cultura hasta comienzos del siglo XXI.

\section{TRES DESCUBRIMIENTOS DEL CABO DE HORNOS}

Un primer descubrimiento ocurrió hace unos 7500 años atrás por los antepasados del pueblo originario yagán (Rivas et al. 1999; Ocampo \& Rivas, 2000). Con hábitos de vida nómade, pescadores, cazadores y recolectores principalmente marítimos y costeros, los yaganes habitaron los archipiélagos del Cabo de Hornos navegando en livianas canoas fabricadas con la corteza de un árbol que domina los bosques subantárticos: el coigüe de Magallanes (Nothofagus betuloides) (Fig. 3). Sus akar o chozas eran construidas con ramas de estos árboles y pieles de lobo marino, montadas sobre cimientos de conchas de bivalvos dando origen a miles de conchales que permanecen hasta hoy en las costas de las islas al sur de Tierra del Fuego, que conservan una de las mayores concentraciones de sitios arqueológicos en el mundo (Ocampo \& Rivas, 2000). Este fue un período de cohabitación biocultural que también nos ha legado una sofisticada cosmogonía, prácticas y conocimiento tradicional ecológico que se expresan hoy en hábitos de pesca y artesanía.

Un segundo descubrimiento tuvo lugar hace unos 400 años por exploradores europeos, cuando 


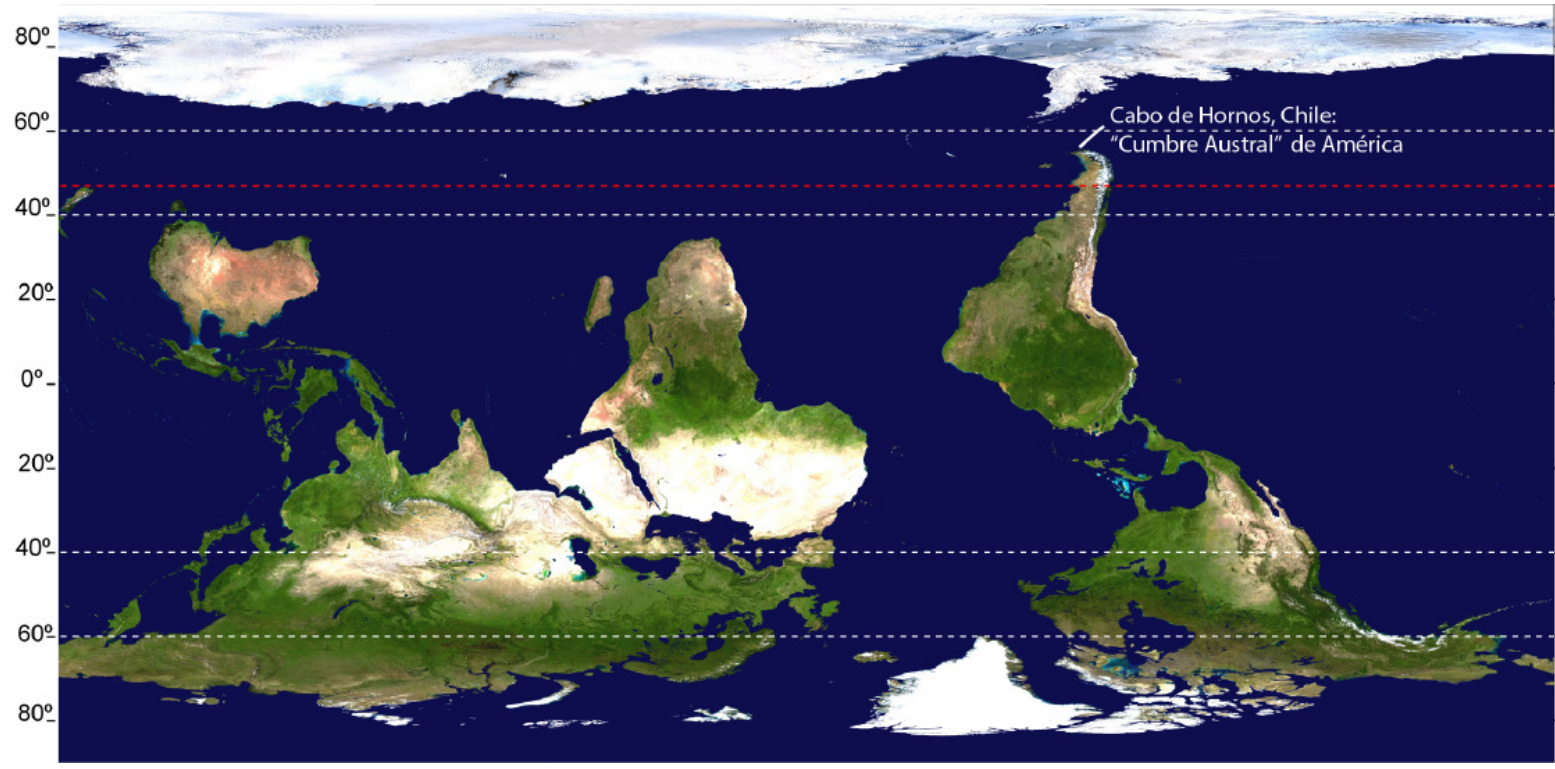

Fig. 1. Mapamundi con el sur arriba, ilustrando cómo Cabo de Hornos emerge como una cumbre de las Américas. La línea entrecortada roja señala la latitud $47^{\circ} \mathrm{S}$ que corresponde a los bosques más australes de Nueva Zelanda. Los bosques de Cabo de Hornos se ubican a $56^{\circ} \mathrm{S}$, casi diez grados de latitud más al sur que los de Nueva Zelanda y representan los bosques más australes del mundo. Las líneas entrecortadas blancas demarcan los ámbitos latitudinales entre 40 y $60^{\circ}$ mostrando el marcado contraste entre los hemisferios sur (predominantemente oceánico) y norte (predominantemente continental). Figura modificada de Rozzi et al. (2012a).
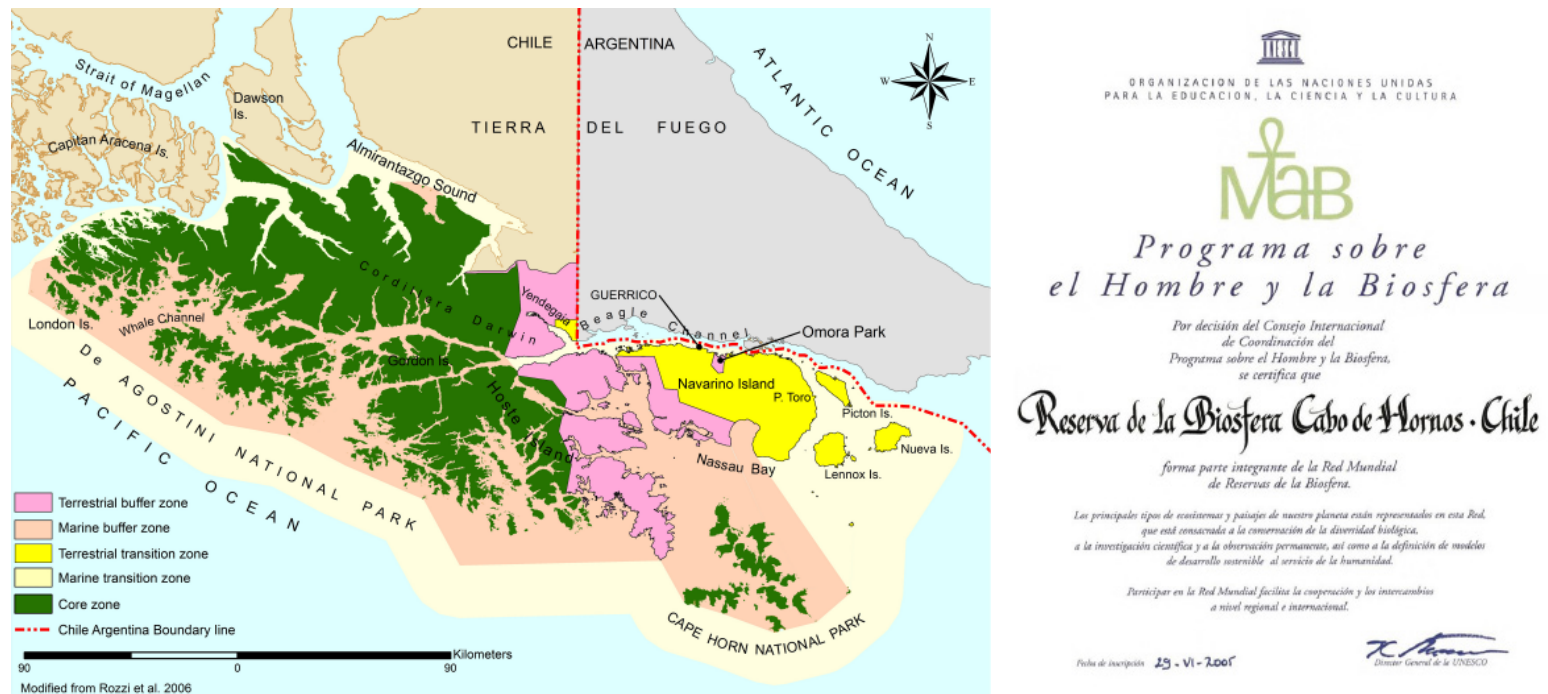

Fig. 2. Izquierda: Mapa de la RBCH indicando su zonificación y la ubicación del Parque Omora en la vecindad de Puerto Williams, isla Navarino. La zonificación incluye tres tipos de zonas: las zonas núcleo (verde), dedicada a la preservación estricta, que en la actualidad incluye a los parques nacionales de Agostini y Cabo de Hornos, y en el futuro incluirá, total o parcialmente, al Parque Nacional Yendegaia; las zonas de amortiguación terrestre (rosado intenso) y marinas (rosado pálido) que permiten actividades de bajo impacto, tales como la pesca artesanal y el turismo de intereses especiales; las zonas de transición terrestre (amarillo intenso) y marina (amarillo pálido) donde se permiten actividades de mayor impacto, incluyendo la construcción de infraestructura. Derecha: Certificado de las Naciones Unidas que creó esta reserva de la biosfera chilena el 25 de junio del año 2005. 

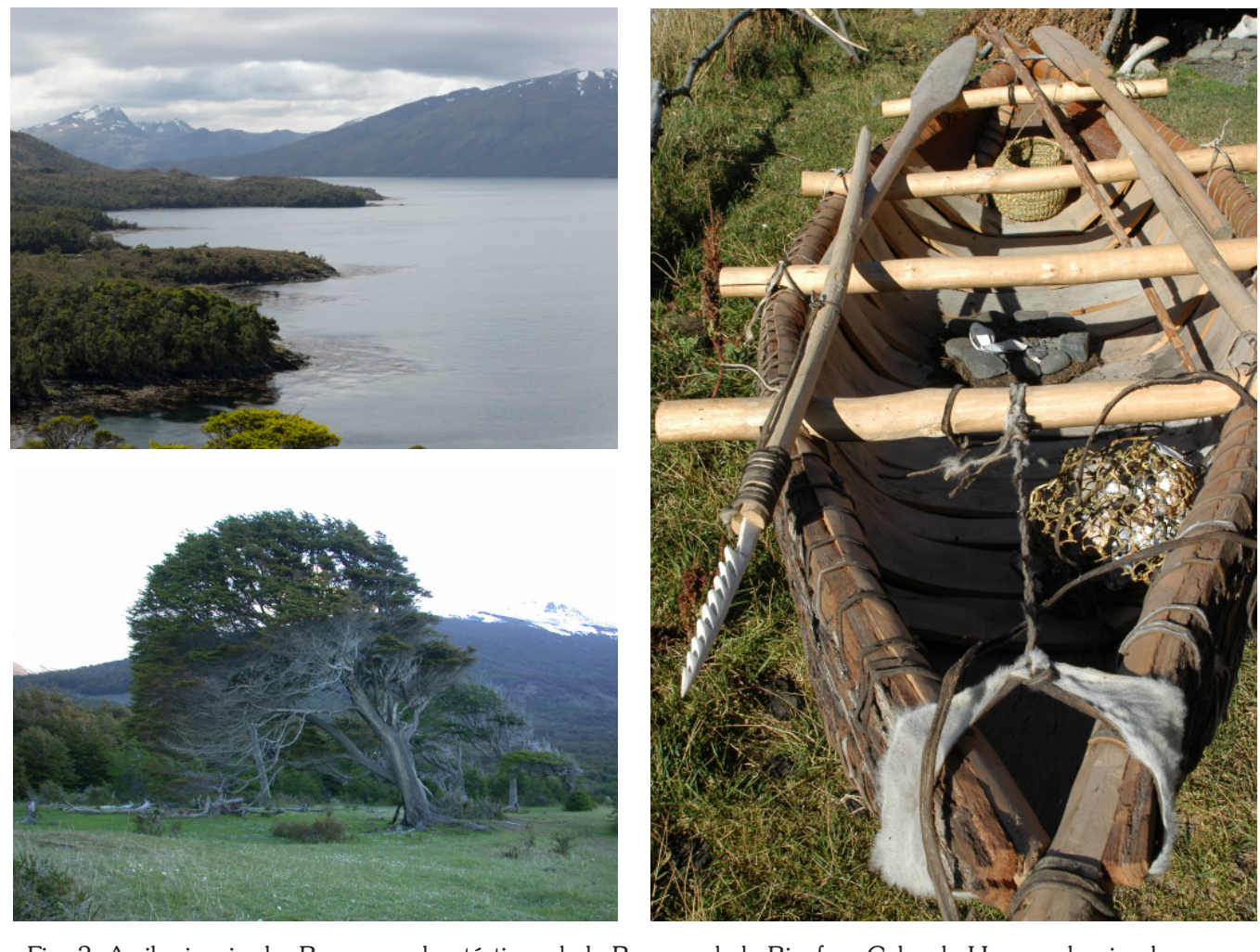

Fig. 3. Arriba izquierda: Bosques subantárticos de la Reserva de la Biosfera Cabo de Hornos dominados por coigüe de Magallanes, Nothofagus betuloides. (Fotografía Jorge Herreros). Abajo izquierda: Acercamiento de un árbol de coigüe de Magallanes (Fotografía John Schwenck). Derecha: Canoa de corteza de coigüe de Magallanes construida por el artesano yagán Martín González. (Fotografía Jordi Plana).

el Cabo de Hornos fue avistado el 29 de enero de 1616 por Jacob Le Maire y Willem Schouten. Estos exploradores holandeses transformaron el paradigma de la cartografía europea del siglo XVII que representaba a Tierra del Fuego adosada al continente antártico. Este paradigma cambió para siempre desde el momento en que el Concordia (Eendracht en holandés), al mando del capitán Schouten, dobló desde el Océano Atlántico hacia el Pacífico un cabo formado por unas montañas puntiagudas. Su expedición había zarpado desde la ciudad holandesa de Hoorn y por esta razón bautizaron al cabo austral con el nombre de Cabo de Hornos (Martinic, 2005). Desde entonces la historia se ha centrado en las odiseas de navegación, cartografía, misiones, actividades económicas asociadas a la caza de ballenas y lobos marinos, la fiebre del oro y más tarde la colonización europea y chilena del archipiélago austral. Este foco antropocéntrico impulsado por el segundo descubrimiento europeo fue expresado concisamente por el guionista y navegante francés
Paul Guimard, quien a fines del siglo XX escribió: El Cabo de Hornos hubiera podido ser para siempre nada más de lo que es: un punto sobre el mapa del mundo. Pero los hombres y los veleros lo han transformado en una epopeya (en Bertea \& Chevallay, 2008, p. 103).

Un tercer descubrimiento del Cabo de Hornos se gestó a partir de un cambio del foco antropocén trico hacia un foco que valoriza la singular biodiversidad que habita en los archipiélagos del extremo austral del continente americano. Este descubrimiento surgió como un evento fortuito, que condujo al descubrimiento que Cabo de Hornos constituye un centro de diversidad de briofitas y líquenes a nivel mundial (Recuadro 1). El estudio y apreciación de esta flora requiere el uso de una lupa que amplíe tanto la imagen de la pequeña flora y otros organismos, como también el espectro de valores asociados esta biota. A su vez, el "observar con lupa" el Cabo de Hornos permitió identificar una nueva ecorregión, única en el planeta: la ecorregión subantártica de Magallanes. 


\section{RECUADRO 1. SERENDIPIA ${ }^{1}$ EN EL ORIGEN DEL ECOTURISMO CON LUPA}

A comienzos del XXI, un grupo de científicos nos embarcamos en la Maroba para iniciar una expedición florística por las islas de Cabo de Hornos. En esta pequeña lancha pesquera capitaneada por Mauricio Zárraga, experimentado pescador de la Comunidad Indígena Yagán de Bahía Mejillones en Puerto Williams, zarpamos en marzo del 2000 navegando por las tranquilas aguas del canal Beagle. Sin embargo, cuando intentamos cruzar la bahía Nassau tuvimos que refugiarnos de fuertes tormentas por varios días en bahía Douglas durante una semana. Con sólo dos días disponibles para trabajar al final de la expedición, cuando mejoró el clima logramos cruzar hacia seno Grandi al sudoeste de isla Navarino. Una vez en tierra iniciamos una frenética búsqueda de especies de musgos muy especializados que podrían crecer sólo sobre huesos de ballenas varadas en las playas subantárticas, y encontré creciendo sobre la turba el primero de estos musgos: Tayloria magellanica (Fig. A).

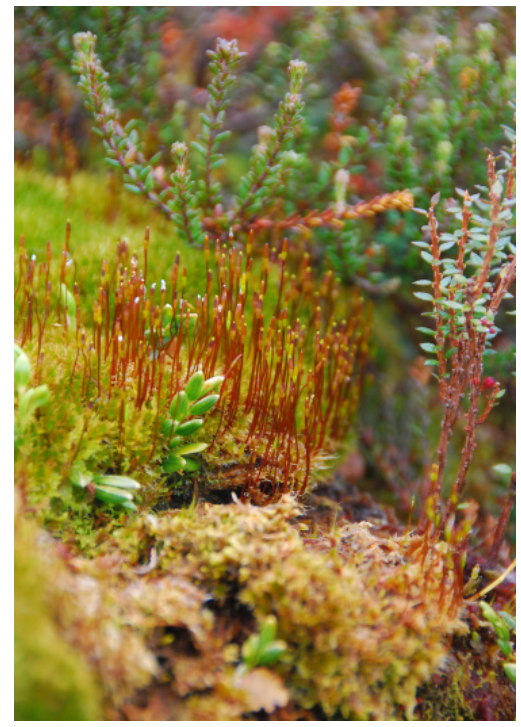

Fig. A. E musgo Tayloria magellanica en turberas del sector sur de la isla Navarino. (Fotografía Ricardo Rozzi).

Cruzábamos las turberas del sur de la isla Navarino cuando me alejé del grupo y en el ánimo de acortar camino intenté saltar sobre una laguna pantanosa, y no llegué a la otra orilla, cayendo en medio de una turbera pantanosa. Empecé a hundirme y llegué a estar seguro que sería una muerte natural tranquila. Al cabo de unas 3 horas, cuando ya me hundía completamente, tuve una epifanía: observé una asombrosa diversidad de musgos y líquenes que crecían con formas muy hermosas y distintas en torno a la laguna del pantano, y pensé: Si yo soy biólogo y no

1 El término "serendipia" fue acuñado en el siglo XVIII por el escritor inglés Horace Walpole, quien tradujo al inglés un cuento persa titulado "The three princes of Serendip" ("Serendip" era la isla de Ceilán, el actual Sri Lanka), en el que los tres príncipes solucionaban sus problemas a través de asombrosos hallazgos casuales. Se utiliza para designar un descubrimiento fortuito o imprevisto. conozco esta diversidad de pequeñas plantas no-vasculares ¿que podríamos esperar de los educadores y tomadores de decisiones ambientales en Chile?

En la década de 1990 había participado en las comisiones de identificación de sitios prioritarios para la conservación de la biodiversidad en Chile y Latinoamérica, con base sólo en especies de vertebrados, especialmente mamíferos y aves, $y$ de grandes plantas vasculares, principalmente árboles, arbustos y lianas (Rozzi, 2012). Bajo ese esquema, Cabo de Hornos quedaba clasificado como "desconocido" y de baja prioridad para la conservación de la biodiversidad a nivel nacional y mundial. Afortunadamente, antes de hundirme completamente en el pantano fui rescatado por el briólogo belga Bernard Goffinet, con quien realizamos una serie de expediciones florísticas y al cabo de cuatro años "eureka": ¡descubrimos que los archipiélagos de Cabo de Hornos constituyen un "hotspot" o centro mundial de diversidad de musgos y hepáticas a nivel mundial!

En menos del $0,01 \%$ de la superficie terrestre del planeta se encuentra más del $5 \%$ de las especies de briófitas (musgos y hepáticas) descritas a nivel mundial (Rozzi et al. 2008). Este reciente descubrimiento ha tenido implicancias no sólo para investigar sino también para conservar la biodiversidad de Cabo de Hornos. Por primera vez en Chile y en el mundo, se propuso un área protegida en base a la diversidad de musgos y hepáticas, que constituyó un argumento central para la creación de la $\mathrm{RBCH}$.

Los musgos son pequeñas plantas que han sido poco percibidas y valoradas no sólo en la ciencia sino también en la conservación internacional. En Cabo de Hornos se gestó un "cambio de lentes" para conservar la biodiversidad a nivel mundial. El mayor conocimiento y valoración sobre esta singular diversidad biológica se incorporó a través de la creación de una innovadora actividad de turismo de intereses especiales: "ecoturismo con lupa" (Rozzi et al. 2012b) (Fig. B). Esta modalidad de turismo sustentable integra las ciencias, las artes y la ética ambiental para apreciar los valores ecológicos, estéticos, económicos y éticos de la biodiversidad de pequeños organismos. De esta manera, desde el Cabo de Hornos se ha planteado una forma distinta de mirar y valorar la flora, y la actividad de ecoturismo con lupa es practicada hoy en Japón, China, Alaska y otras regiones subpolares del mundo.

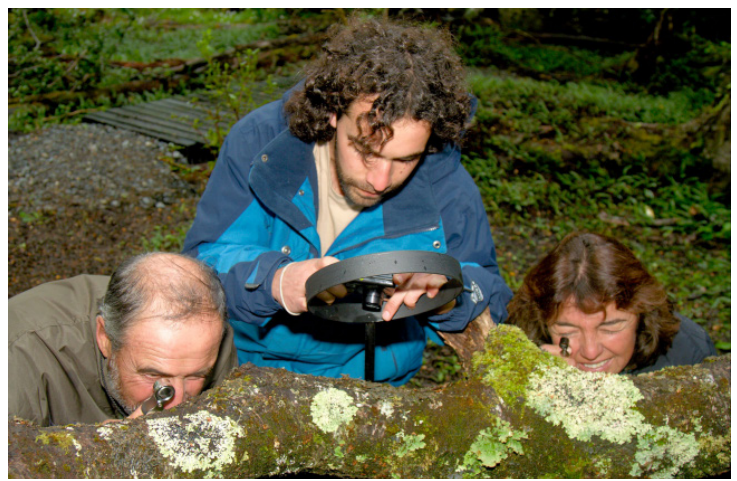

Fig. B. Una familia practicando "ecoturismo con lupa" en el Parque Omora. (Fotografía Adam Wilson). 
Hasta el año 2000 la singularidad biogeográfica del sudoeste de Sudamérica permanecía invisible para la ciencia, la política y la sociedad, debido a la prevalencia de la imagen de la Patagonia. Ésta evoca principalmente el sudeste de América del Sur caracterizado por la estepa árida y plana, habitada por pueblos cazadores terrestres y en el período postcontacto europeo por gauchos y estancieros ganaderos y petroleros. En contraste, en el margen sudoeste del continente la región es lluviosa, montañosa y boscosa, habitada originalmente por pueblos canoeros marítimos $y$ en los últimos cinco siglos por navegantes, exploradores europeos, pescadores y la Armada de Chile. Estos archipiélagos chilenos permanecían como terra incognita y por eso se propuso llamarlos ecorregión subantártica de Magallanes (Rozzi, 2001; Rozzi et al. 2012b) (Fig. 4). Esta nominación ha facilitado descubrir

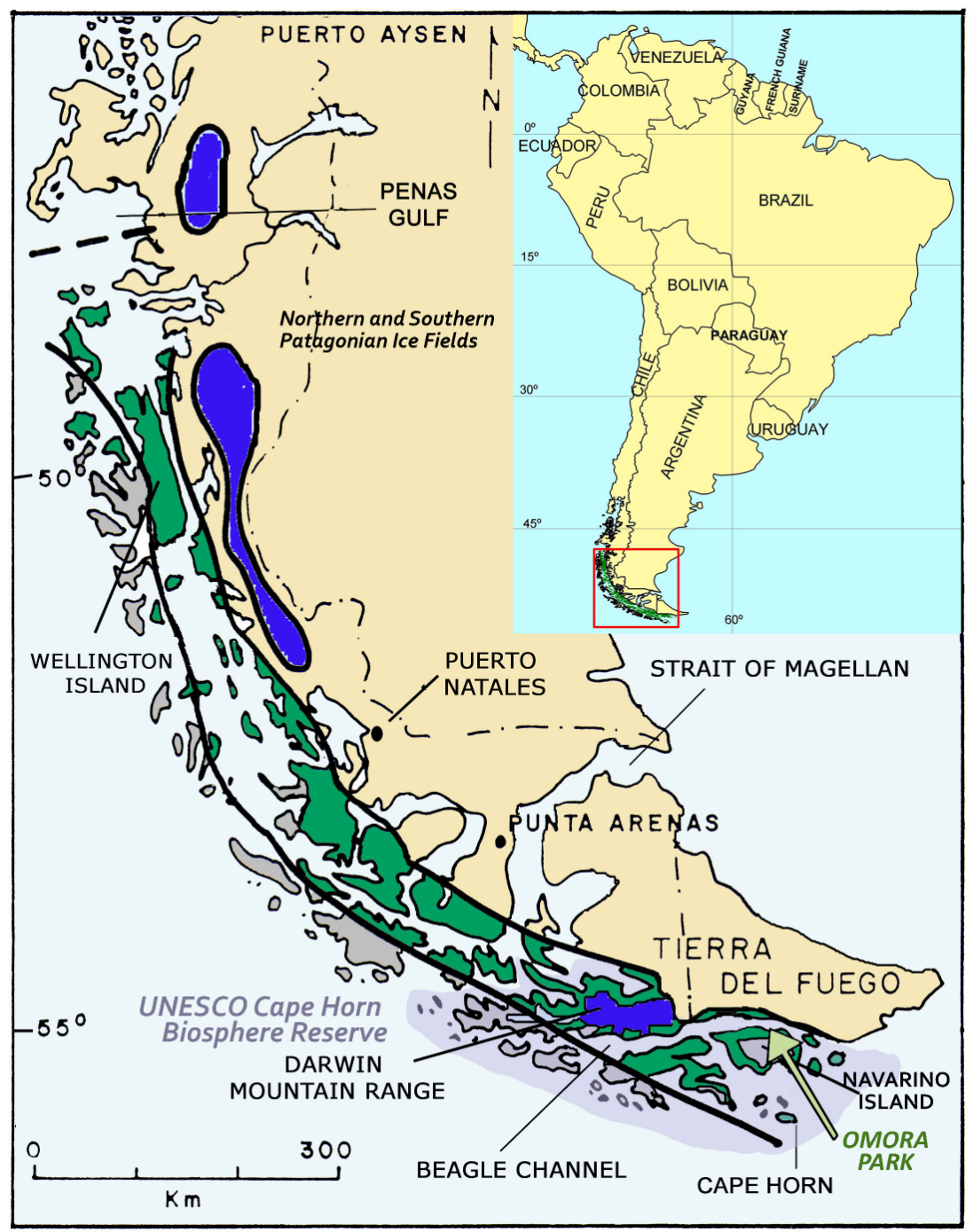

Fig. 4. La ecorregión subantártica de Magallanes se extiende desde el Golfo de Penas $\left(47^{\circ} \mathrm{S}\right)$ hasta el Cabo de Hornos (56 S). Se muestra la distribución de los bosques siempreverdes dominados por coigüe de Magallanes (verde) y del complejo de tundra de Magallanes (gris). La Reserva de la Biosfera Cabo de Hornos (púrpura) se ubica al sur de esta ecorregión. El

Parque Omora ubicado en la isla Navarino sirve como sitio de investigación ecológica a largo plazo en esta ecorregión. Figura modificada de Rozzi et al. (2008). 
y reconocer en su singularidad a una región extrema.

En este artículo nos centraremos en la identificación de un atributo que resalta el valor especial de la biodiversidad de la $\mathrm{RBCH}$ : sus múltiples relaciones biogeográficas. Se ensayará un prisma de una red de afinidades con biotas de seis regiones biogeográficas contrastantes: antárticas, bipolares (subárticas y subantárticas), circumantárticas, gondawánicas, neotropicales y altoandinas, con un énfasis en la flora no-vascular (briofitas) y liquénica, considernado también su alto grado de endemismo. Este ejercicio ha resultado de los inventarios florísticos (Goffinet et al. 2012) y de la práctica del "ecoturismo con lupa" en la Reserva de la Biosfera Cabo de Hornos (Rozzi et al. 2012b). Aporta un análisis emergente, que complementa el análisis de la distribución geográfica de flora vascular leñosa del bioma de los bosques templados de Sudamérica desarrollado por Carolina Villagrán (2018), donde ella examina tres elementos biogeográficos principales: endémico, neotropical y australantártico/australasiano (Schmithüsen, 1956; Villagrán \& Hinojosa, 1997, 2005; Villagrán \& Armesto, 2005).

\section{CABO DE HORNOS: UN CRISOL BIOGEOGRÁFICO}

La $\mathrm{RBCH}$ presenta un marcado gradiente de precipitación desde el oeste hacia el este.

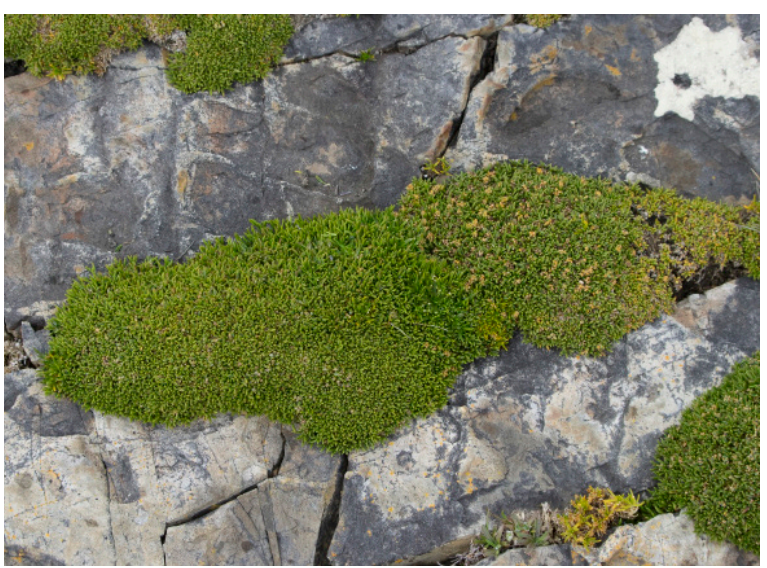

Cuando los vientos del oeste que transportan alta humedad desde el Océano Pacífico chocan con la cordillera Darwin, la humedad se condensa y precipita en forma de lluvia en las tierras bajas y en forma de nieve en las montañas (Tuhkanen et al. 1990). En solo $300 \mathrm{~km}$, desde el oeste hacia el este, la precipitación anual disminuye en un orden de magnitud: desde aproximadamente 5000 mm en las costas del Pacífico al oeste de la Cordillera Darwin hasta $500 \mathrm{~mm}$ en Puerto Williams. La combinación de factores climáticos, orográficos y biológicos da origen a un mosaico de ecosistemas terrestres que incluyen bosques, matorrales, tundras y humedales, hábitats altoandinos, islas expuestas al océano Pacifico y glaciares (Rozzi et al. 2007). En este mosaico de ecosistemas, una de las mayores singularidades de la biodiversidad de la $\mathrm{RBCH}$ está asociada a la variedad de relaciones biogeográficas (Moore, 1983). Su biota tiene afinidades con al menos seis regiones biogeográficas contrastantes que revisaremos concisamente, con un foco en la flora de briófitas (musgos y hepáticas) y líquenes, que posee además un alto grado de endemismo, y forma lo que hemos llamado metafóricamente los bosques en miniatura del Cabo de Hornos (Rozzi, 2012).

\section{Afinidades antárticas}

La flora del Cabo de Hornos y de la Antártica es única entre los biomas del mundo,

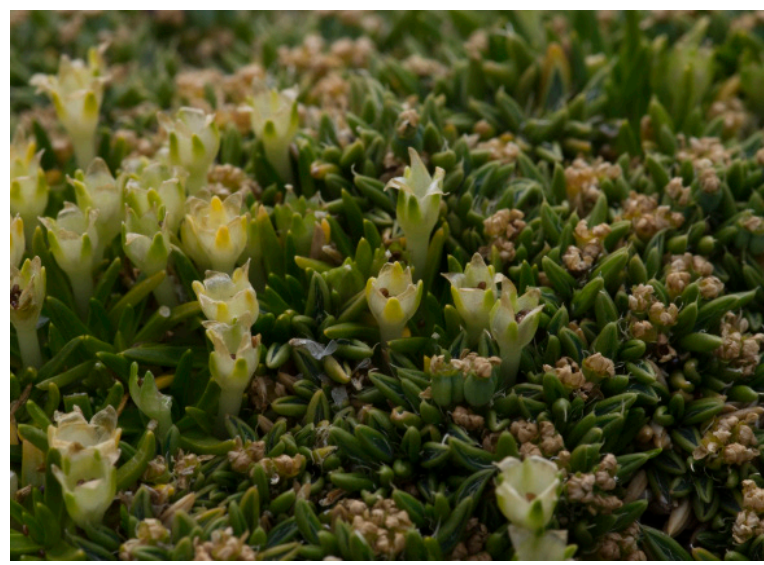

Fig. 5. Izquierda: En las costas del Parque Omora crece en forma de "planta en cojín" el clavel antártico (Colobanthus quitensis), que también crece en el continente antártico. Derecha: Ésta es una especie de planta con flor característica de las regiones subantárticas y Antártica marítima. Fotografías Jorge Herreros. 

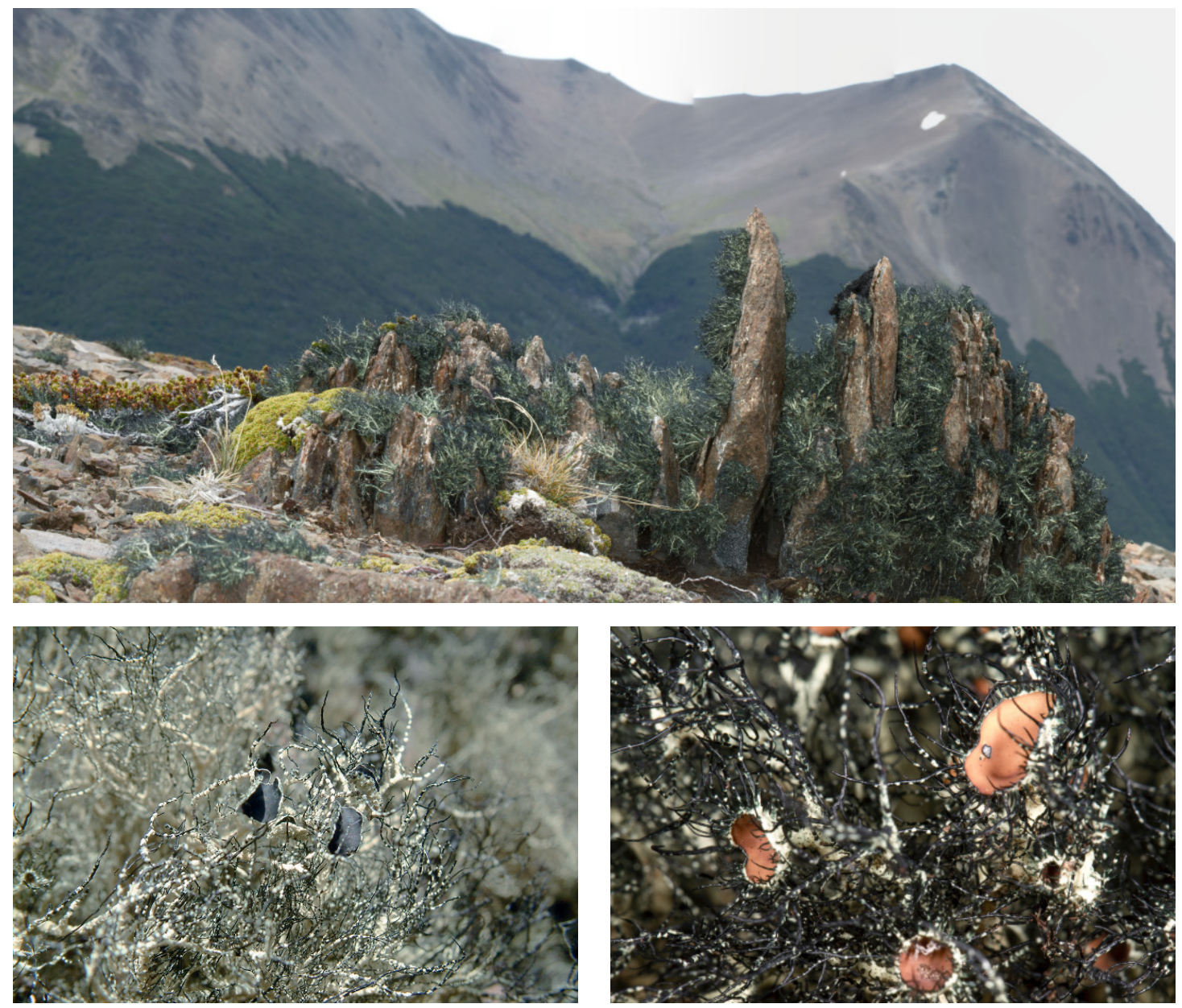

Fig 6. Arriba: En la zona altoandina del Parque Omora se encuentran líquenes que crecen sobre rocas y que también crecen en en la Península Antártica. Abajo: Usnea aurantiacoatra (izquierda) y U. trachycarpa (derecha) ofrecen un buen ejemplo de las afinidades biogeográficas entre la Antártica y la ecorregión subantártica de Magallanes. Sus cuerpos reproductivos o apotecios se asemejan a un plato negro (U. aurantiaco-atra) o rosado (U. trachycarpa).

Fotografías de Adam Wilson (arriba) y Leopoldo Sancho (abajo).

puesto que está dominada por pequeñas plantas no-vasculares (o briófitas) y por líquenes. Esta dominancia es extrema en el caso de la Península Antártica donde sólo crecen dos plantas nativas vasculares: el pasto antártico (Deschampsia antarctica) y el clavel antártico (Colobanthus quitensis), que también crece en las islas del archipiélago Cabo de Hornos (Fig. 5).

A nivel de musgos y líquenes, sin embargo, la Península Antártica y Cabo de Hornos comparten decenas de especies (Goffinet et al. 2012). Ejemplos notables de líquenes antárticos se encuentran en las cumbres de las montañas y en las costas subantárticas de Magallanes. Sobre las rocas de las cumbres de la $\mathrm{RBCH}$ crecen dos especies de líquenes del género Usnea que caracterizan la flora antártica: U. aurantiaco-atra y U. subantarctica. Estas especies resaltan por su morfología ramosa y poseer apotecios en forma de discos rosados y negros, respectivamente (Fig. 6). Estos líquenes sintetizan ácido úsnico que filtra la fuerte radiación ultravioleta. Este ácido ha sido usado crecientemente para preparar cosméticos y medicinas, incluyendo una forma que inhibe un virus asociado a varios tipos de cáncer. Los líquenes antárticos y de las montañas subantárticas albergan el secreto de la síntesis de compuestos únicos, pero la mayoría 

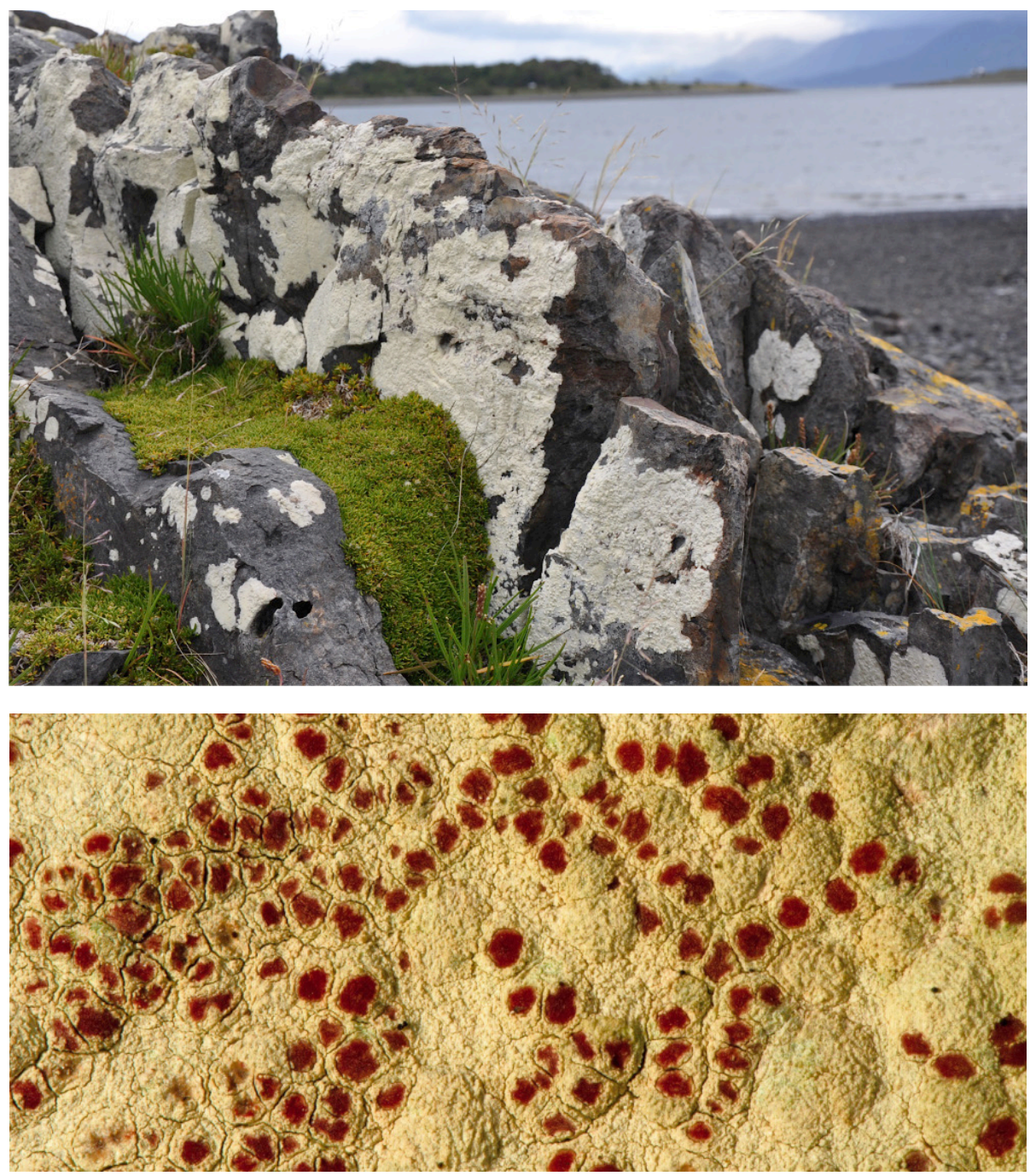

Fig. 7. Arriba: Sobre las rocas del nivel más alto del intermareal (alejado del agua) en las costas subantárticas de la $\mathrm{RBCH}$ y de la Península Antártica, se observa una capa cremosa continua que corresponde al liquen Haematomma erythromma, Abajo:

Acercamiento que revela el significado del nombre científico de este liquen que posee talos crustosos de color amarillo pálido y apotecios de color rojo oscuro, dan la impresión

de un hematoma (del griego haimato- "sangre" + -ōma "tumor"), es decir, como una acumulación de sangre causada por una hemorragia de eritrocitos (del griego erythrós

"rojo" + kytos "célula") o glóbulos rojo de la sangre. Fotografías Adam Wilson.

de las especies aún permanece inexplorada en cuanto a sus propiedades biológicas.

Las costas antárticas y subantárticas también comparten especies de líquenes comunes, tales como Haemmatoma erythroma que genera una capa cremosa continua en las rocas donde expande sus talos crustosos de color amarillo pálido salpicados por conspicuos apotecios rojos (Fig. 7). En las playas antárticas y subantárticas es frecuente observar asimismo una textura diferente generada por los talos ramificados de Ramalina terebrata que crece sobre las superficies de rocas protegidas (Fig. 8). Este liquen crece especialmente donde hay acumulación de guano de aves. De hecho, dos especies de pingüinos antárticos, el pingüino 


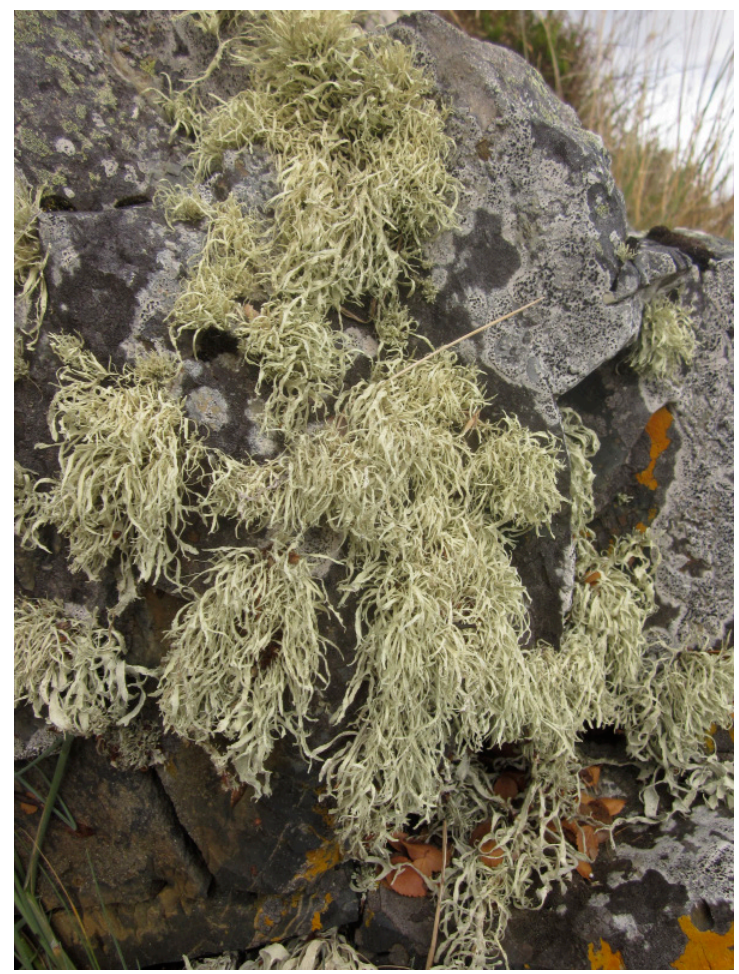

Fig. 8. Izquierda: El liquen Ramalina terebrata sólo crece en la ecorregión subantártica de Magallanes y en la Península Antártica e islas antárticas, principalmente en rocas protegidas del impacto directo del rocío o "spray" del oleaje marino. Derecha: Esta especie de liquen se caracteriza porque sus talos son muy ramificados. Fotografías de Gonzalo Arriagada.

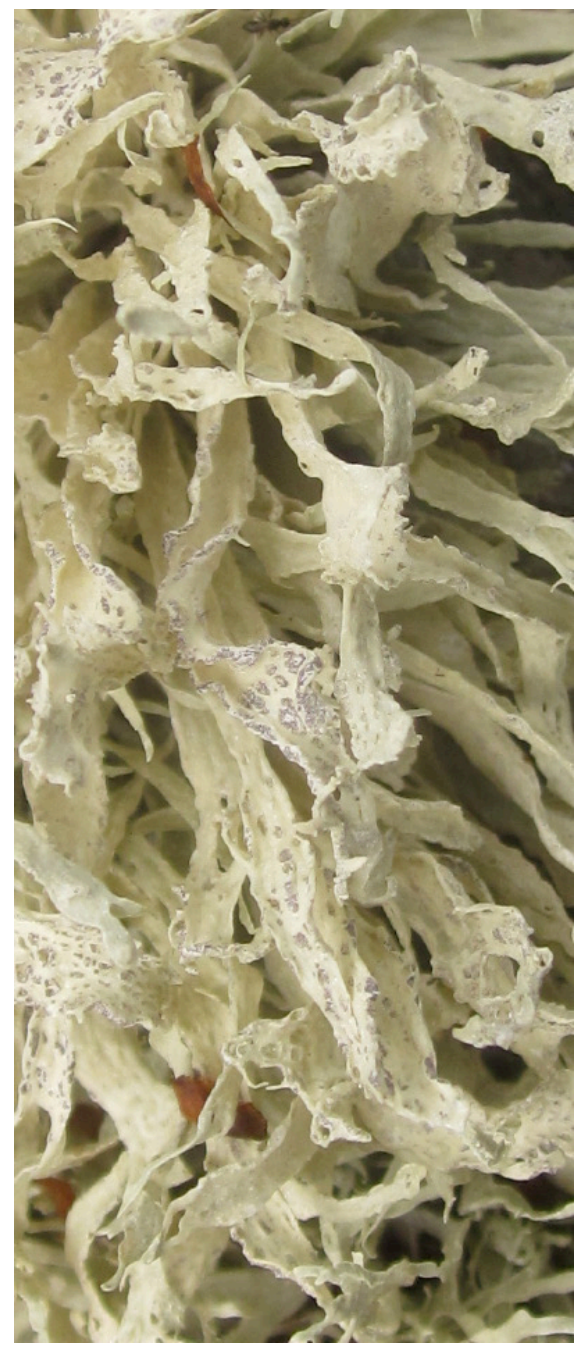

macaroni (Eudyptes chrysolophus) y el pingüino de barbijo (Pygoscelis antárctica) visitan ocasionalmente las costas de Cabo de Hornos realzando las interconexiones antárticas y subantárticas (Couve \& Vidal, 2003). El liquen Ramalina terebrata posee compuestos químicos con fuertes propiedades antibacterianas efectivas para el tratamiento de enfermedades infecciosas, especialmente del patógeno Staphylococcus aureus. Otros líquenes llamativos son aquellos que generan el color naranja brillante que marca el límite superior de la marea alta en la zona intermareal. Entre ellos, Caloplaca hookeri y C. sublobata crecen profusamente sobre las rocas de la costa en la Península Antártica y la Reserva de la Biosfera Cabo de Hornos (Fig. 9).
Distribuciones bipolares

Las regiones polares, subantárticas y subárticas, comparten un número de especies que solo crecen en las altas latitudes de ambos hemisferios o en las cumbres de altas montañas en latitudes intermedias. Este patrón de distribución es llamado "bipolar". Una especie de liquen característica de altas latitudes y altitudes de los hemisferios norte y sur es la "lana de roca" (Pseudephebe pubescens) (Fig. 10). Crece sobre rocas graníticas donde extiende sus ramificados talos negros. Los pigmentos negros sirven para filtrar la intensa radiación ultravioleta y aumentar la absorción de la radiación solar incidente, incrementando la temperatura de sus tejidos en las 

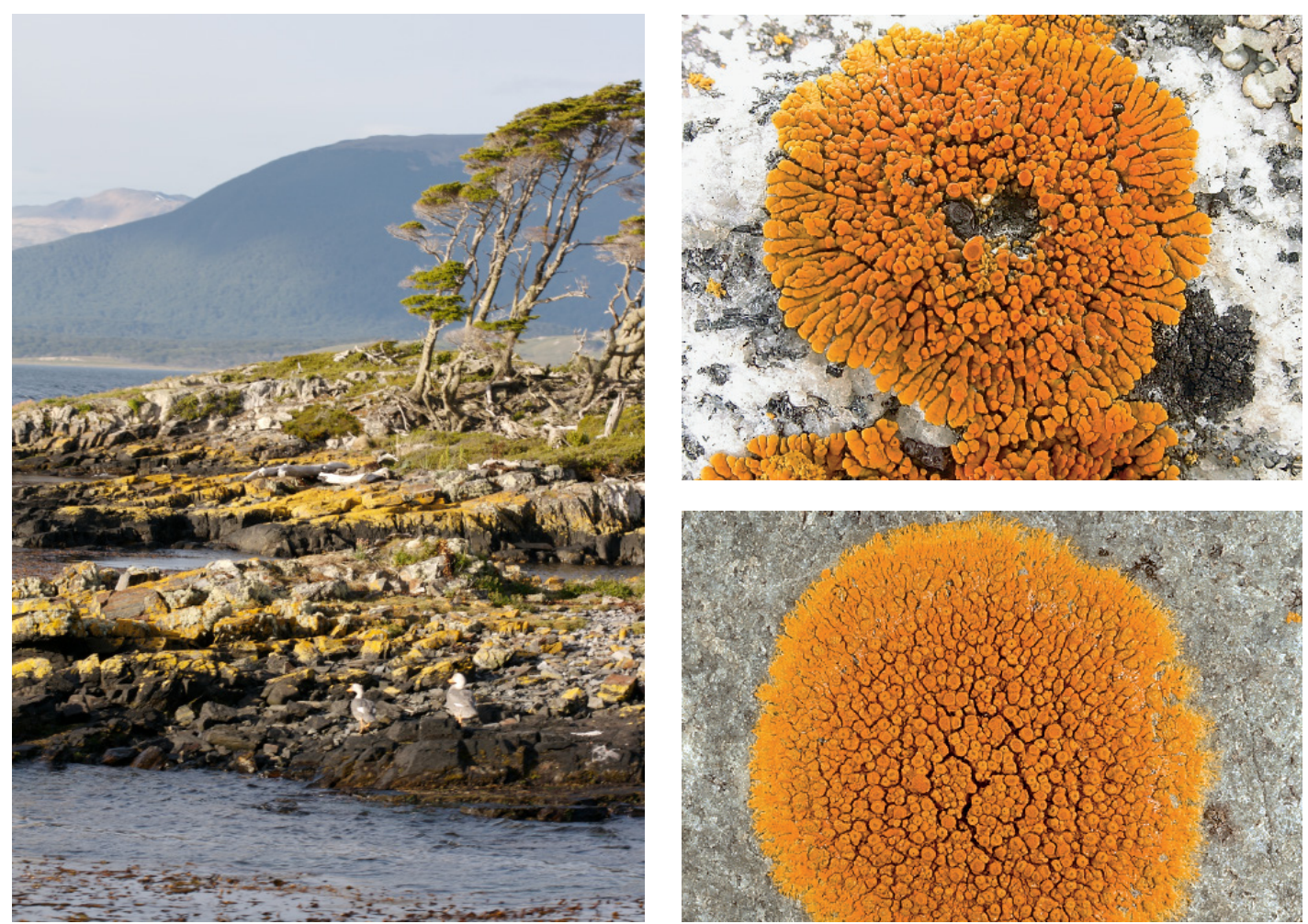

Fig. 9. Izquierda: En rocas costeras por sobre la línea de alta marea en las costas antárticas y subantárticas crecen líquenes del género Caloplaca que dan un característico color anaranjado a estos ecosistemas.

Derecha: Dos especies de Caloplaca comunes en la Reserva de Biosfera Cabo de Hornos son C. hookeri (arriba) y C. sublobulata (abajo). El talo crustoso de estas especies penetra las rocas a través de los diminutos espacios entre los cristales minerales, encontrando refugio contra el exceso de radiación y la deshidratación. Alcanzan la superficie para producir sus apotecios o estructuras reproductivas con forma de discos aplanados de brillante color naranja desde donde dispersan sus esporas. Esta estrategia de vida ha permitido a estos líquenes colonizar ambientes extremos. Fotografías de Ulrik Søchting.
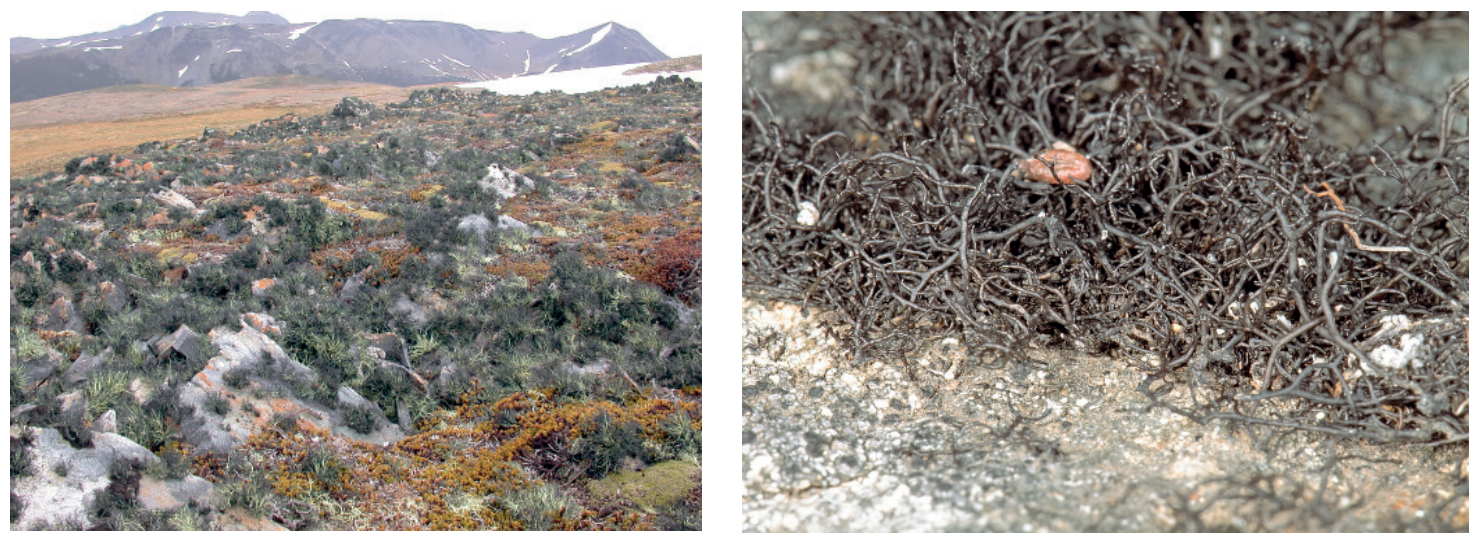

Fig. 10 Izquierda: Un caso paradigmático de distribución bipolar se encuentra en la zona altoandina del parque Omora y otras cumbres de la Reserva de la Biosfera Cabo de Hornos donde crece el liquen llamado "lana de roca" porque sus talos se extienden sobre las rocas y ramifican como una madeja de lana. Derecha: Este liquen Pseudephebe pubescens se caracteriza por sus hábitos rastreros. Fotografias de Adam Wilson. 

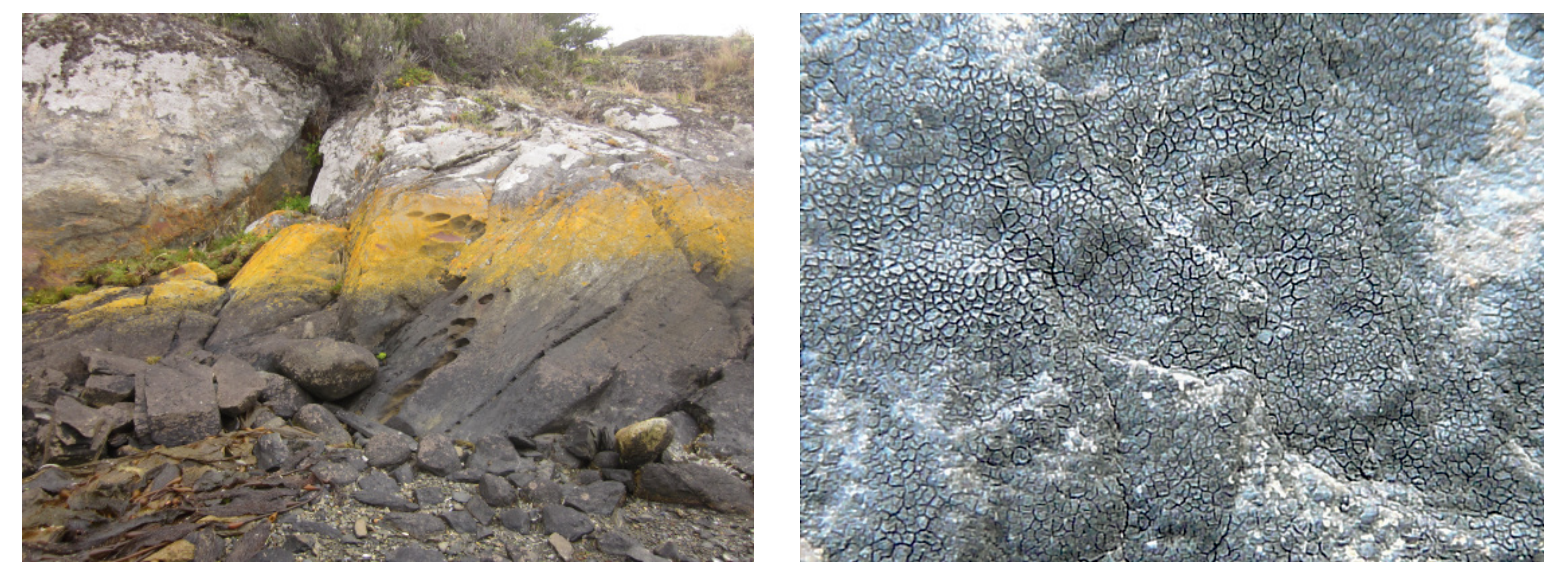

Fig. 11. Izquierda: Sobre las rocas de las costas de las zonas subpolares de los hemisferios sur y norte se detecta una banda negra en la zona inferior del intermareal que corresponde a finos líquenes del género Verrucaria.

Derecha:Esta especie se caracteriza por su talo negro crustoso con una red de fisuras y con apotecios que están mayoritariamente hundidos y sobresalen levemente como conos. Fotografías de Adam Wilson.

frías regiones subpolares. Es muy abundante en las cordilleras de la isla Navarino, donde a diferencia de las especies de Usnea con las que suele crecer, los talos de Pseudephebe se extienden apegados al sustrato, mientras que los de Usnea crecen más bien erguidos y son parcialmente amarilloverdosos.

Otro liquen bipolar abundante en Cabo de Hornos crece en las costas, sobre las paredes rocosas del intermareal y que a simple vista podría confundirse con manchas de petróleo. El liquen Verrucaria maura queda sumergido durante las horas de alta marea y reaparece bajo las bandas anaranjadas de Caloplaca y blancas de Haematomma en los momentos de baja marea con su característico color negruzco (Fig. 11). Con una lupa puede observarse claramente que su talo oscuro está roto en diferentes areolas más o menos ordenadas que le dan el aspecto típico de barro seco agrietado.

Entre los musgos bipolares sobresale Tetraplodon fuegianus (Fig. 12). Recientemente se descubrió que este musgo endémico del extremo sudoeste de Sudamérica tiene su especie evolutivamente hermana, T. mnioides, en la costa oeste de Norteamérica (Lewis et al. 2014a). Más de un tercio de las especies de musgos que crecen en la Reserva de la Biosfera de Cabo de Hornos (Buck \& Goffinet, 2010; Méndez et al. 2013) tienen una relación evolutiva con poblaciones de la misma especie o del mismo género de la región subártica de Norteamérica. Para conectar ambas floras, desde los tiempos de Charles Darwin se ha propuesto a las aves migratorias que vuelan entre las regiones subpolares del Continente Americano como los vectores más probables de su dispersión a larga distancia. Sin embargo, esta propuesta se había limitado a las especies de "plantas superiores", es decir, aquellas que poseen flores, frutos y semillas.

Bajo este paradigma darwiniano, un ejemplo icónico de distribución bipolar corresponde a los pequeños arbustos del género Empetrum, cuyos frutos son consumidos por aves y que posee sólo dos especies en el mundo: E. rubrum, la murtilla, con frutos rojos (Lat. rubrum) restringida al sudoeste de Sudamérica y zonas subantárticas aledañas (Fig. 13), y E. nigrum, la baya de cuervo, con frutos negros (Lat. nigrum) confinada a las zonas subárticas del Hemisferio Norte (Donoghue, 2011; Popp et al. 2011). En contraste, para las "plantas inferiores" (los musgos y otras briófitas) se había propuesto que su capacidad para dispersarse dependía exclusivamente de mecanismos físicos, o abióticos, como el viento.

En Cabo de Hornos y toda la región circumsubantártica, los vientos prevalecientes corresponden a los vientos del oeste o westerlies que son particularmente fuertes en esta latitud austral. Por lo tanto, se ha propuesto que la composición de las floras de briofitas subantárticas está gobernada por las corrientes de viento que 

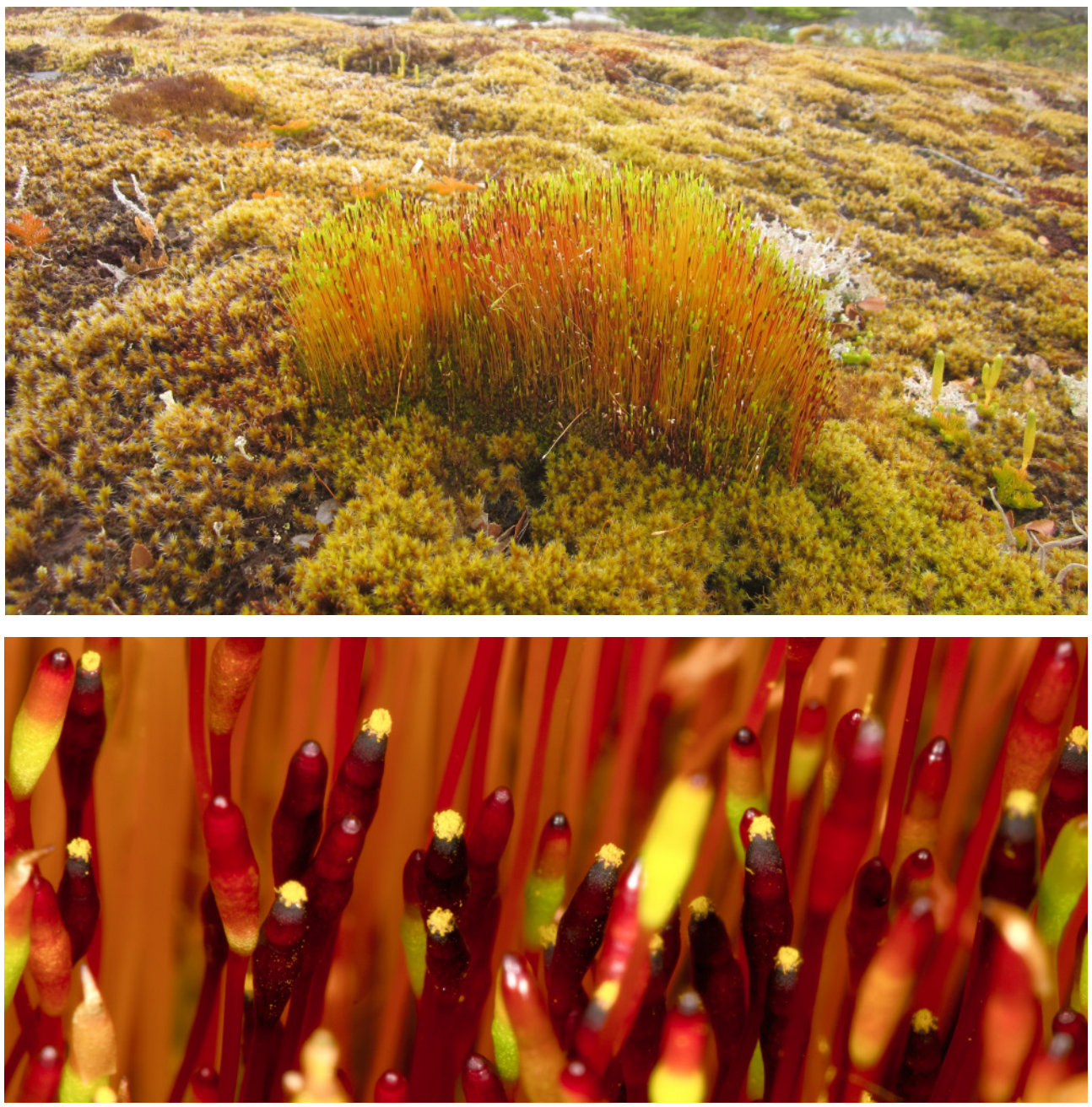

Fig. 12. Arriba: En las turberas de la Reserva de la Biosfera Cabo de Hornos crece un musgo con distribución bipolar: Tetraplodon fuegianus, que tiene su origen evolutivo en Norteamérica cerca de Alaska. Abajo: Las cápsulas de este musgo son muy llamativas, cargadas de esporas amarillas, listas para ser dispersadas. Fotografías de Adam Wilson.

permiten superar las barreras impuestas por las masas oceánicas y conectar a las biotas de las islas y áreas continentales en estas latitudes altas del Hemisferio Sur (Muñoz et al. 2004). El reciente descubrimiento de la distribución bipolar del musgo Tetraplodon fuegianus y su especie hermana en Alaska, T. mnioides, complejizó, sin embargo, este paradigma darwiniano en tres aspectos fundamentales: (i) no sólo las grandes plantas vasculares sino también las pequeñas briófitas son dispersadas por aves migratorias a largas distancias; (ii) la dirección de la dispersión a larga distancia de las briófitas subantárticas de
Magallanes no sólo ocurre en dirección oesteeste sino también sur-norte; (iii) la biota del Cabo de Hornos no está tan aislada, como se pensaba hasta hace muy poco, sino que está interconectada con otras biotas subpolares del planeta (Lewis et al. 2014b). Este último hecho cobra la mayor relevancia en el contexto del cambio climático, puesto que bajo condiciones climáticas más cálidas podrían dispersarse y establecerse nuevas especies de plantas que modificarán la flora de Cabo de Hornos. Al mismo tiempo, este descubrimiento muestra la relevancia de realizar ciencia de excelencia en 

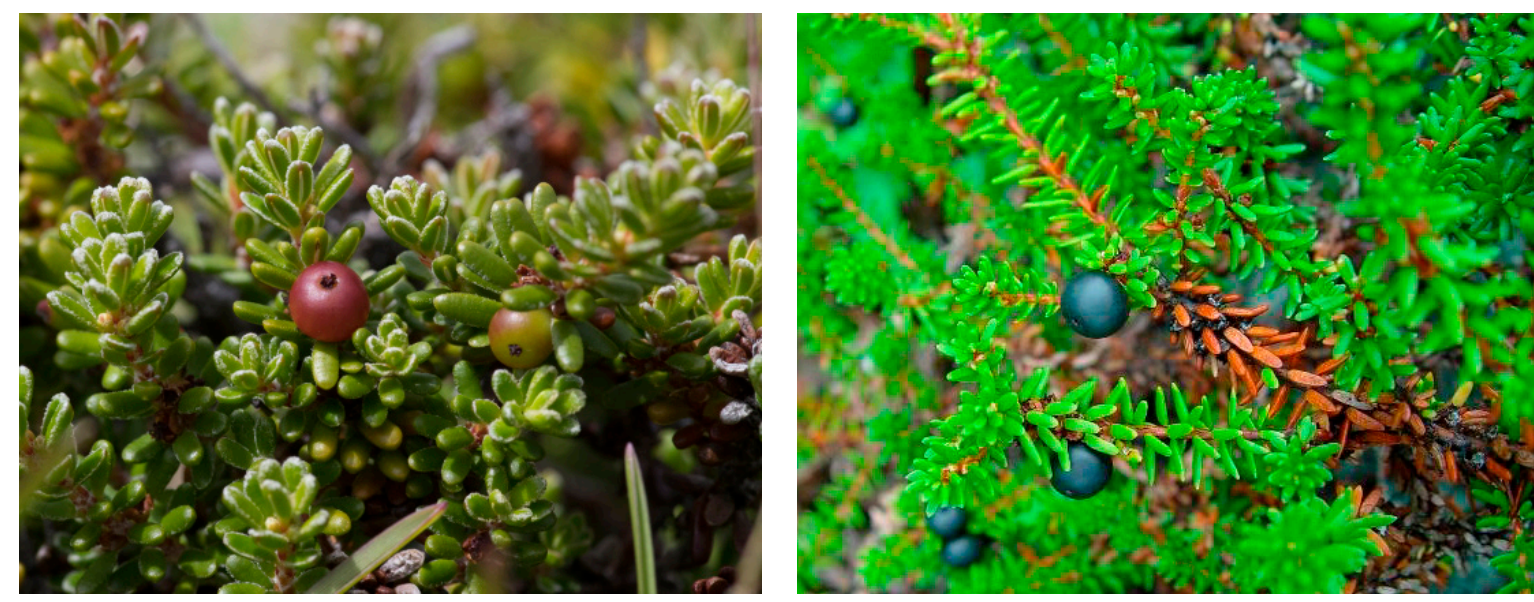

Fig. 13. Entre las plantas vasculares de la $\mathrm{RBCH}$, un arbusto del género Empetrum representa un caso paradigmático de distribución subpolar: E. rubrum con frutos rojos (izquierda, fotografía Jorge Herreros). El arbusto congenérico $E$. nigrum posee frutos negros y se distribuye solo en el hemisferio norte (derecha, fotografía Arthur Haines).

las zonas extremas de Chile, cuyas biotas son excepcionales a nivel mundial.

\section{Distribución circumsubartántica}

Los fuertes vientos circumsubantárticos transportan las esporas de musgos y líquenes a grandes distancias. Aunque numerosas esporas son dispersadas, son pocas las que sobreviven el viaje y menos aún aquellas que arriban a un hábitat adecuado para su crecimiento. Sin embargo, la dispersión repetida durante millones de años aumenta la probabilidad que algunas esporas establezan una nueva población en un sitio distante. Este es el caso de un musgo singular: Orthotrichum crassifolium. En la mayoría de los musgos las esporas germinan después de su dispersión, en cambio, en $O$. crassifolium las esporas comienzan a dividirse mientras aún están dentro de la cápsula, y se dispersan en grupos compactos de células generando una ventaja al inicio del desarrollo de su progenie. Además, posee una tolerancia a condiciones de salinidad que le permite crecer al borde de los mares subantárticos en las rocas del litoral afectadas por la espuma del mar (Fig. 14). Su estrategia reproductiva y tolerancia a la salinidad le han permitido ser el único "musgo marino" en el mundo y haber alcanzado una amplia distribución circumpolar, creciendo en la costa de la mayoría de las islas subantárticas.

\section{Distribución gondwánica}

Hace unos 200 millones de años Sudamérica, África, Australia y Antártica estaban unidas en un bloque continental austral denominado Gondwana. En el presente la distribución de los árboles del género Nothofagus constituyen un ejemplo ilustrativo de las antiguas conexiones gondwánicas, puesto que sus especies se encuentran sólo en el Hemisferio Sur, en Australasia (este y sudeste de Australia, Nueva Zelanda, Nueva Guinea y Nueva Caledonia) y en el sur de Sudamérica (Chile y Argentina) (Veblen et al. 1996). Árboles fósiles también se conservan en la Antártica (Li \& Zhou, 2007). Los bosques de la RBCH están dominados por tres especies de Nothofagus: el coigüe de Magallanes ( $N$. betuloides), la lenga ( $N$. pumilio) y el ñirre (N. antárctica) (Fig. 15).

Sobre el suelo de estos bosques de Nothofagus, como también en los de Tasmania, Nueva Zelanda y Nueva Guinea, crecen varias especies de musgos con distribución gondwánica, tales como Bartramia mossmaniana, que sobresale por sus hojas arqueadas y sus llamativas estructuras reproductivas 0 esporofitos con cápsulas redondeadas estriadas (Fig. 16). Sobre los troncos de Nothofagus en Cabo de Hornos y otros bosques gondwánicos el musgo más común es Lepyrodon lagurus (Fig. 17), que forma densas y suaves alfombras sobre la corteza de los árboles generando un revestimiento esponjoso 

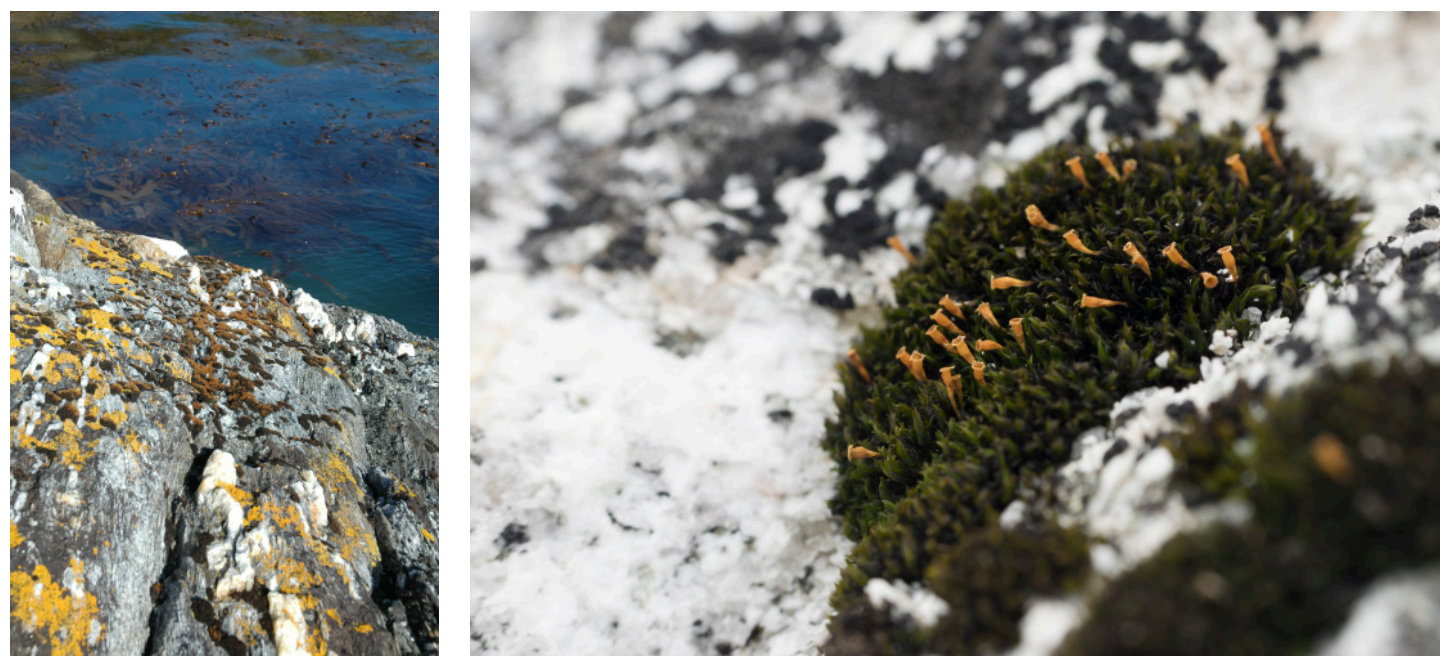

Fig. 14. Izquierda:Orthotrichum crassifolium tiene una amplia distribución circumpolar en las islas subantárticas a través del Océano Austral donde crece exclusivamente sobre las rocas al borde del mar. (Fotografía de Ricardo Rozzi). Derecha: Este musgo cece en pequeños cojines de color verde oscuro-negruzco y los esporofitos tde color amarillo pálido emergen sobre las hojas. (Fotografía de Jorge Herreros).
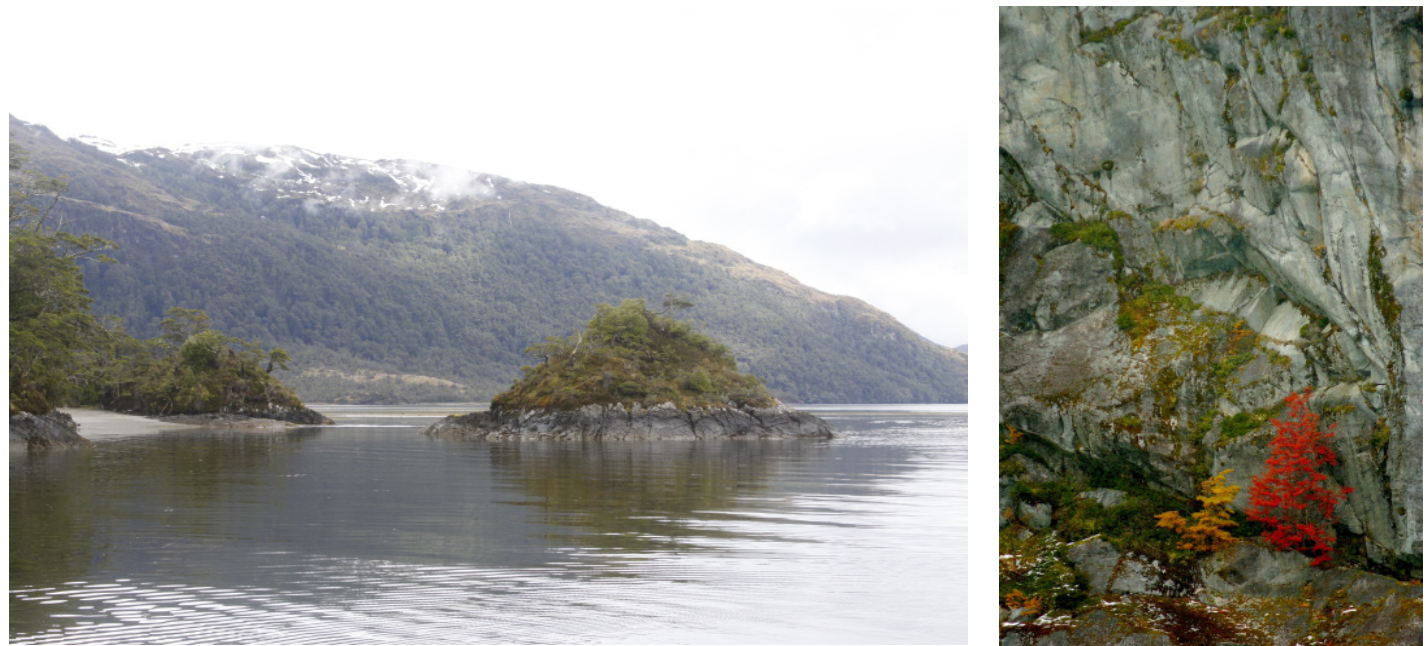

Fig. 15 Izquierda: Los bosques siempre verde dominados por coigüe de Magallanes (Nothofagus betuloides) a nivel del mar y altitudes bajas (Fotografía Paola Vezzani). Derecha: A mayores alitudes dominan otras dos especies del género Nothofagus que son caducifolias: la lenga ( $N$. pumilio; hojas de color rojo) y el ñirre ( $N$. antárctica; hojas de color amarillo). (Fotografía Jordi Plana).

que retiene el agua y contribuye a la regulación de los ciclos hidrológicos. La amplia distribución de este y otros musgos puede interpretarse como resultado de la separación de continentes que estuvieron originalmente unidos en Gondwana. Alternativamente, la distribución amplia podría ser el resultado de la dispersión a larga distancia $y$ el establecimiento de esporas que encontraron recientemente (en términos evolutivos) hábitats apropiados en los bosques de Nueva Zelanda, Tasmania y Cabo de Hornos.

\section{Afinidades neotropicales}

Los bosques costeros siempreverdes de hoja ancha de la $\mathrm{RBCH}$ presentan algunas sorprendentes conexiones biogeográficas con bosques neotropicales de América del Sur y 

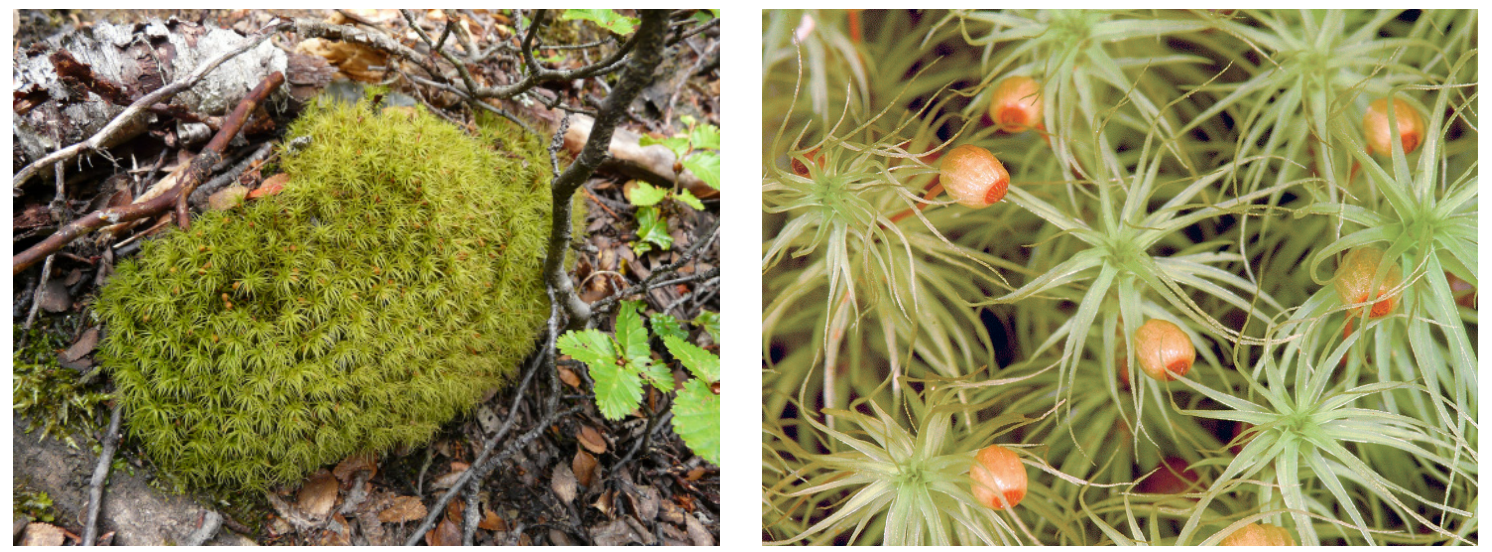

Fig. 16. Izquierda: En el suelo de los bosques de Nothofagus de la Reserva de Biosfera Cabo de Hornos crecen especies de musgos con distribución gondwánica que son abundantes como Bartramia mossmanian. (Fotografía Lily Lewis). Derecha: Sus esporofitos poseen cápsulas inconfundibles, con forma de manzana, por eso en el Parque Omora lo denominamos "musgo manzana". (Fotografía Adam Wilson).
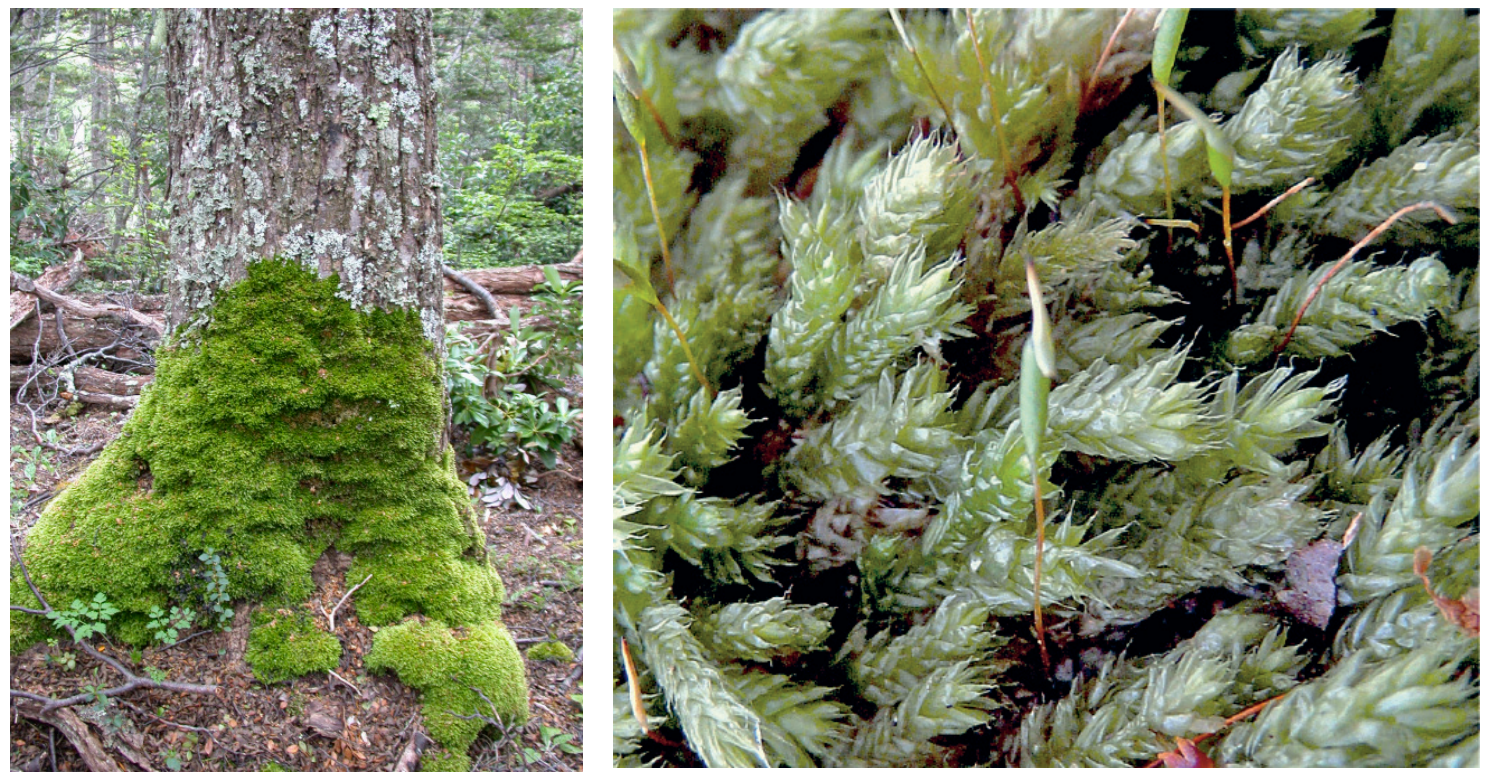

Fig. 17. Izquierda: Sobre los troncos de los árboles del género Nothofagus en la Reserva de Biosfera Cabo de Hornos crece en gran abundancia un musgo con distribución gondwánica: Lepyrodon lagurus.

(Fotografía Lily Lewis). Derecha: Sus hojas son erectas y muy puntiagudas; sus esporofitos sobresalen con un tallo café y una cápsula elongada. (Fotografía Adam Wilson).

Central. En estos bosques resalta el canelo, Drimys winteri, con sus características hojas anchas y siempreverdes (Fig. 18). El género Drimys posee especies que se distribuyen a lo largo de América del Sur y Central alcanzando el sur de México (Arroyo et al. 1996a,b). El canelo es la especie más meridional y alcanza los bosques subantárticos de la isla Hornos donde es un árbol dominante cuyos frutos carnosos son consumidos por el fío-fío (Elaenia albiceps). Esta ave migratoria se alimenta de estos frutos antes de volar cada otoño desde el Cabo de Hornos hacia la selva amazónica en Brasil (Jiménez et al. 2016). En los bosques costeros siempreverdes sorprende también observar en latitudes subantárticas bandadas de loros y ocasionalmente colibríes, aves características de las latitudes tropicales de América (Rozzi \& Jiménez, 2014). 


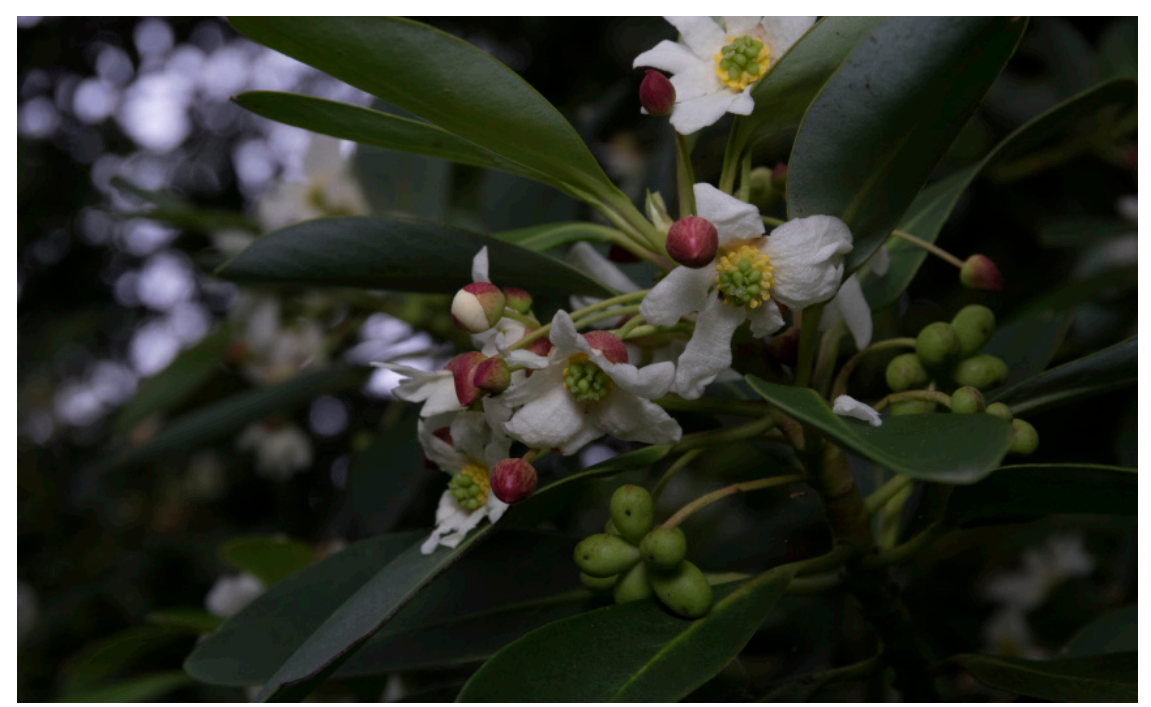

Fig. 18. Un caso conspicuo de planta perteneciente a un género de distribución neotropical es el canelo, Drimys winteri. Posee características hojas anchas, lanceoladas que pueden llegar a medir $20 \mathrm{~cm}$ y son siempreverdes; su flor es blanca con el centro amarillo y su fruto es una baya que provee alimento para las aves frugivoras. (Fotografía Jorge Herreros).

Afinidades altoandinas

Las regiones de altas latitudes y altitudes comparten similitudes ambientales debido a que en ambas disminuye la temperatura y tienen climas rigurosos. En las biotas altoandinas de la $\mathrm{RBCH}$ las plantas y las aves en cojín ofrecen buenos ejemplos de conexiones con la biota de la alta Puna Andina. Por encima del límite arbóreo se encuentran los hábitats alto-andinos, caracterizados por bajas temperaturas, fuertes vientos y estaciones muy cortas de crecimiento y reproducción de las plantas. A primera vista estos ambientes severos pueden parecer "desiertos". Sin embargo, si miramos con atención y nos acercamos al suelo, nos podremos maravillar al descubrir la sorprendente diversidad de pequeñas plantas con llamativas flores y de líquenes y musgos que habitan entre las piedras o asociados con las demás plantas. Uno de los grupos de plantas más sorprendentes y abundantes en la vegetación altoandina son las plantas en cojín, formadas por cientos o miles de pequeñas plantitas de la misma o distintas especies que crecen apegadas unas con otras protegiéndose del fuerte viento y las frías temperaturas. Al observar con lupa estos cojines vegetales podemos distinguir varios tipos de plantas, tales como Bolax gummifera, que tiene la textura de una goma al tocarlos con el dedo y un olor muy distintivo, o especies del género Azorella que se caracteriza por sus hojas suculentas como deditos únicos o trifurcados (Fig. 19). Dentro de estos cojines se forma un microclima que actúa como un pequeño invernadero, donde las oscilaciones térmicas son mucho menores y las condiciones de temperatura más benignas que en los suelos desnudos que los rodean. Por esta razón, en estos cojines vegetales encontramos verdaderos jardines donde crece una gran variedad de musgos, líquenes y algunas pequeñas plantas con flores.

Es notable cómo las plantas en cojín del género Azorella que en los Andes de Bolivia, Perú, norte de Chile y Argentina crecen por sobre los $4000 \mathrm{~m}$ de altitud (Armesto et al. 1980), en Cabo de Hornos llegan a crecer a menos de $1000 \mathrm{~m}$ de altitud o incluso cerca de la costa. Análogamente, las perdicitas cordilleranas habitan en los Andes a una altura de $4000 \mathrm{~m}$ hasta Ecuador. Son aves muy resistentes y no descienden a las partes bajas incluso en condiciones muy duras. Sin embargo, su especie hermana, la perdicita cordillerana austral (Attagis malouinus), es endémica de los hábitats altoandinos de Magallanes donde descienden hasta los $400 \mathrm{~m}$ de altitud (Rozzi \& Jiménez, 2014) (Fig. 20).

Otra ave especializada en los hábitats altoandinos de Cabo de Hornos es el yal cordillerano (Melanodera xanthogramma xanthogramma), que se distribuye hacia el norte por sobre el límite arbóreo en las vertientes andinas de Magallanes (Couve \& Vidal, 2003). Melanodera xanthogramma es endémica de Cabo de Hornos y Tierra del Fuego. Es un ave residente y las poblaciones del archipiélago Cabo de Hornos se desplazan hacia sectores más protegidos en la isla Navarino durante el invierno 

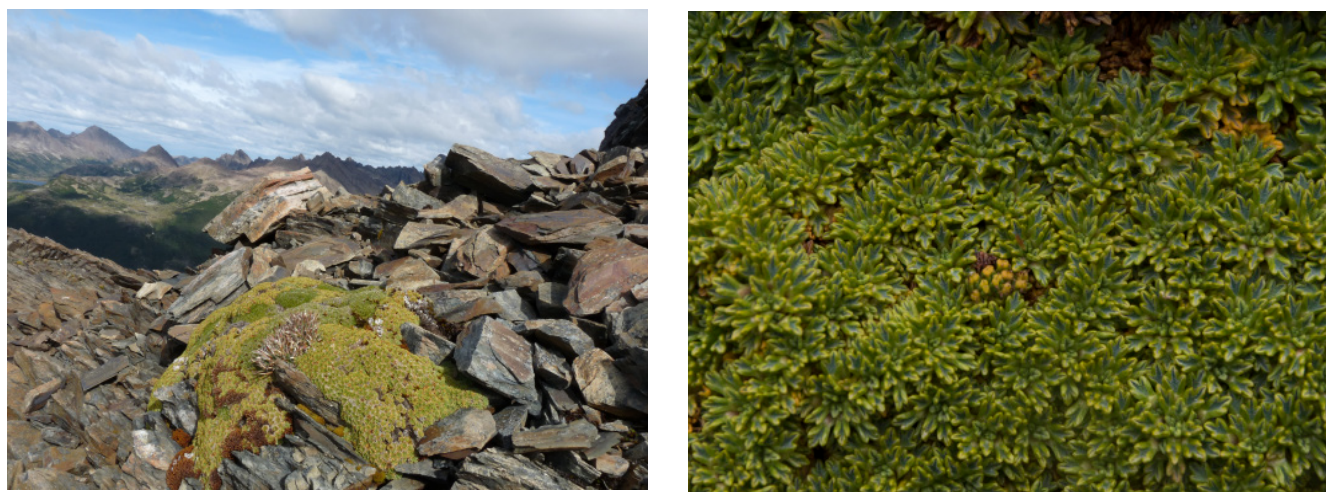

Fig. 19 Izquierda: En la zona altoandina de la Reserva de la Biosfera Cabo de Hornos crecen diversas y abundantes plantas en cojín. (Fotografía Manuela Méndez). Derecha: Las plantas en cojín están formadas por agregaciones de cientos o miles de individuos que crecen unos apegados con otros como se aprecia en este Bolax gummifera. (Fotografía Jorge Herreros).

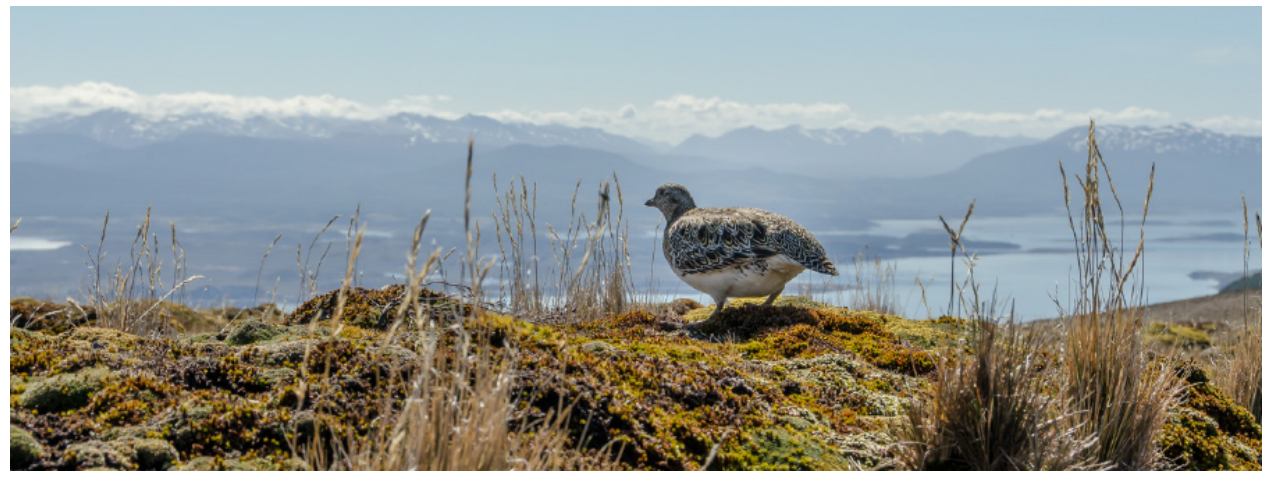

Fig. 20. La perdicita cordillerana austral (Attagis malouinus) sólo anida en zonas altandinas del extremo sur de Chile y Argentina, donde las condiciones pueden ser frías, extremadamente ventosas y duras incluso en pleno verano. (Fotografía Omar Barroso).

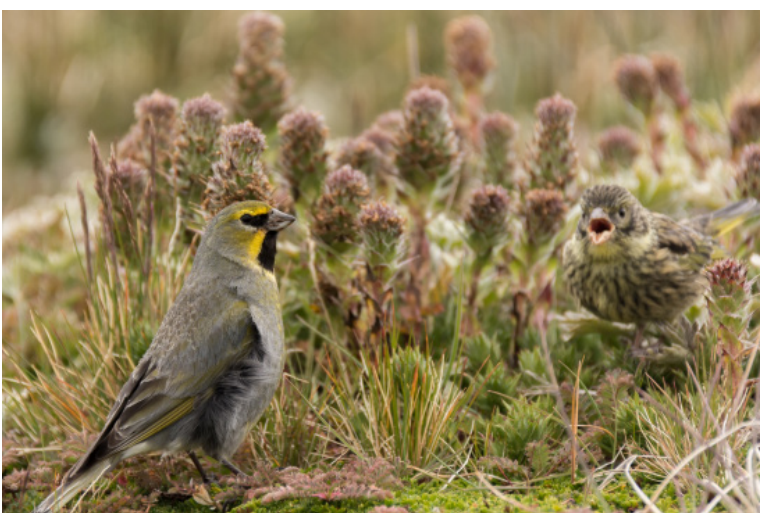

Fig. 21. En las zonas altoandinas de la Reserva de la Biosfera Cabo de Hornos habita la subespecie de yal cordillerano Melanodera xanthogramma xanthogramma, endémica del extremo sur de Chile y Argentina. Los machos poseen una llamativa coloración, en cambio la hembra y los machos jóvenes son moteados pardo-grisáceos. (Fotografía Omar Barroso).
(Rozzi \& Jiménez, 2014). El macho es muy llamativo con su coloración amarilla y gris con manchas negras alrededor de la cara y el cuello, en cambio la hembra y los machos jóvenes son más crípticos, con un gris moteado ligeramente amarillento (Fig. 21). Las perdicitas cordilleranas y los yales cordilleranos constituyen uno de los mayores atractivos para el turismo especializado en birdwatching. La combinación de los efectos climáticos y ambientales de la alta latitud y altitud genera hábitats únicos que están habitados por una singular flora y avifauna subantártica que encuentra en la $\mathrm{RBCH}$ un refugio para su protección y valoración biocultural.

\section{Alto endemismo}

El Cabo de Hornos representa el extremo austral del bioma de los bosques templados de 
Sudamérica que se encuentra aislado de los bosques tropicales más cercanos por 1500 a 2000 kilómetros (Armesto et al. 1998). Este aislamiento geográfico causado por barreras topográficas y climáticas (la alta cordillera de los Andes, la árida estepa Argentina y el hiperárido Desierto de Atacama) ha generado un nivel de endemismo notablemente alto en las plantas. Entre las especies leñosas, cerca del $90 \%$ es endémico de este bioma austral (Arroyo et al. 1996a,b). Más aún, varias especies, como la flor regional de Magallanes, el coicopihue (Philesia magellanica), pertenecen a una familia endémica: Philesiaceae (Marticorena et al. 2010). Las hermosas flores tubulares de esta enredadera proveen una importante fuente de néctar para el picaflor chico y abejorros nativos (Fig. 22).

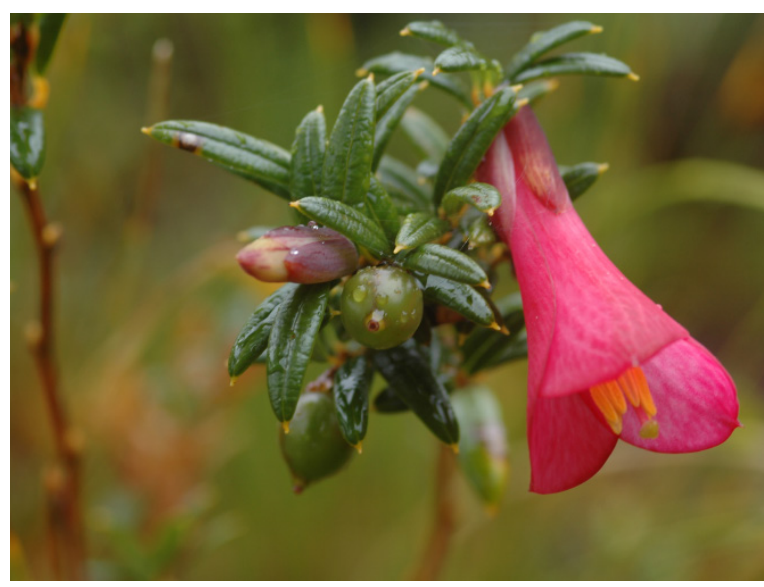

Fig. 22. El coicopihue (Philesia magellanica), es una enredadera endémica. (Fotografía Ricardo Rozzi).
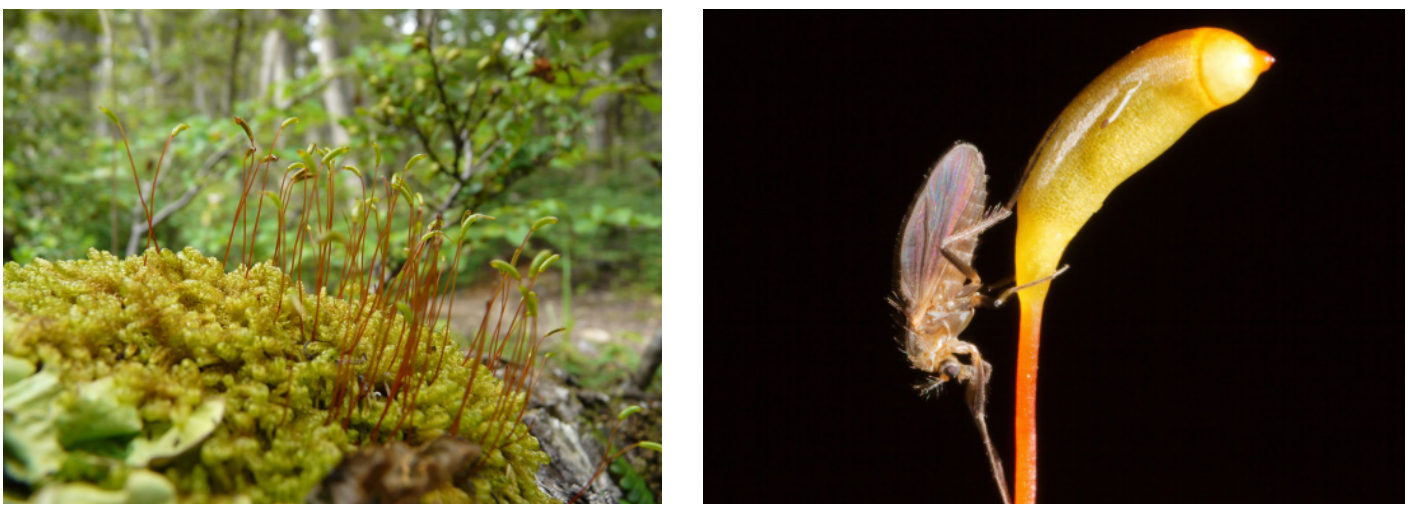

Fig. 23 Izquierda: Hypnum skottsbergii es un musgo endémico del sudoeste de Sudamérica que abunda en la Reserva de la Biosfera Cabo de Hornos. Crece principalmente sobre la corteza troncos en descomposición. (Fotografía Lily Lewis). Derecha Posee largas setas que alcanzan los $20 \mathrm{~mm}$ de longitud, con cápsulas levemente inclinadas y curvadas con una superficie muy lisa. (Fotografía Adam Wilson).

El endemismo también prevalece en las briofitas de Cabo de Hornos: más del $60 \%$ de las especies de musgos y hepáticas son endémicas al bioma de los bosques templados de Sudamérica (Villagrán et al. 2005). Entre las especies de musgos endémicos, Hypnum skottsbergii posee un alto valor estético y cumple un papel ecológico clave al crecer sobre troncos en descomposición y base de los árboles en bosques de Nothofagus (Fig. 23). Entre las hepáticas endémicas, Gackstroemia magellanica resalta por su intenso color café rojizo y talo ramificado semejante a la fronda de un helecho (Fig. 24). Para esta especie se ha propuesto que podría ser endémica del sudoeste de Sudamérica entre los $40^{\circ} \mathrm{S}$ (bosque valdiviano) y $56^{\circ} \mathrm{S}$ (Cabo de Hornos) (Goffinet et al. 2012), aunque la misma especie podría tener más

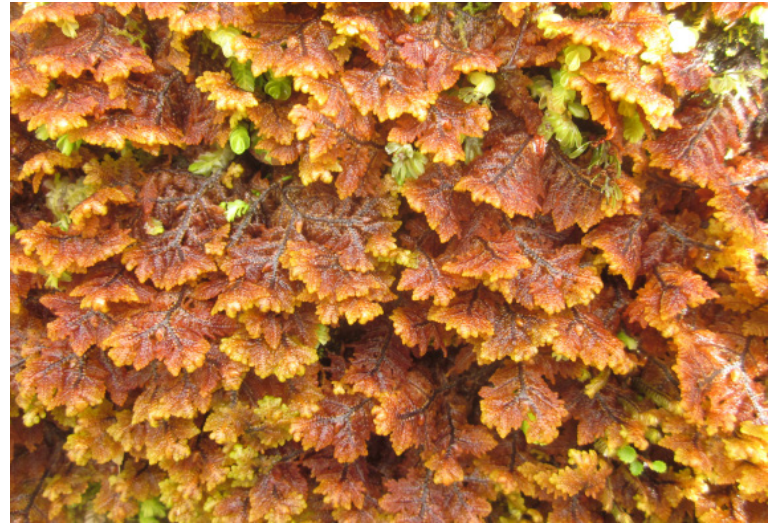

Fig. 24. Hepática endémica (Gackstroemia magellanica) resalta por su intenso color café rojizo y talo ramificado, y su crecimiento formando tapices sobre troncos podridos, turberas o rocas. (Fotografía Stuart Harrop). 
amplia en otras islas subantárticas. Más delicadas son las hojas de otra hepática endémica que abunda en Cabo de Hornos, Plagiochila elata, que posee finos esporofitos traslúcidos (Fig. 25). Plagiochila es el género de hepática con más especies en el mundo, pero $P$. elata es una especie endémica del sudoeste de Sudamérica. Hace 450 millones de años la Tierra era inhóspita para organismos fotosintéticos complejos y los ancestros de las plantas terrestres desplegaron los primeros intentos de colonización. En la actualidad, las briofitas son los parientes vivientes de los primeros colonizadores del ambiente terrestre y en Cabo de Hornos han encontrado un refugio, donde incluso prolifera un grupo enigmático de briofitas que apareció algo más tarde en la evolución de las plantas: los antocerotes. Una especie, Nothoceros endiviifolius, prolifera de forma exuberante sobre el suelo y los troncos de los bosques costeros de la Cordillera Darwin. Al observarlo con lupa impresionan sus grandes órganos sexuales que emergen en forma de cuernos (de donde proviene su nombre griego: anthos $=$ flor; keras $=$ cuerno) (Fig. 26).

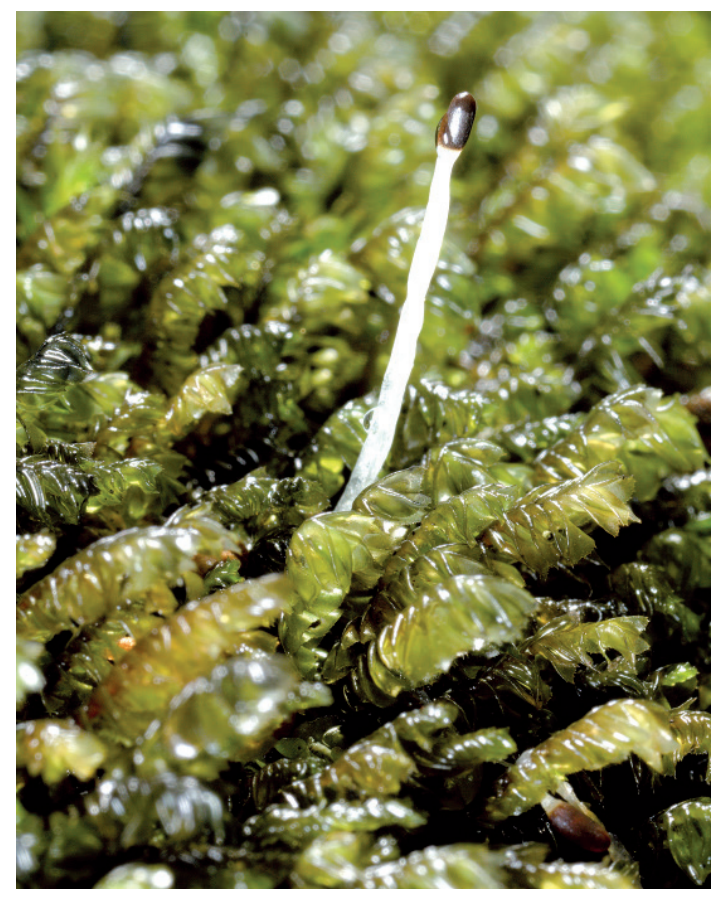

Fig. 25. Plagiochila elata es una hepática endémica del sudoeste de Sudamérica, que se caracteriza por sus tallos algo arqueados con hojas sobrepuestas generalmente en la dirección del ápice del tallo. El esporofito de las hepáticas posee una característica seta blanca- transparente y cápsula negra.

(Fotografía Adam Wilson).

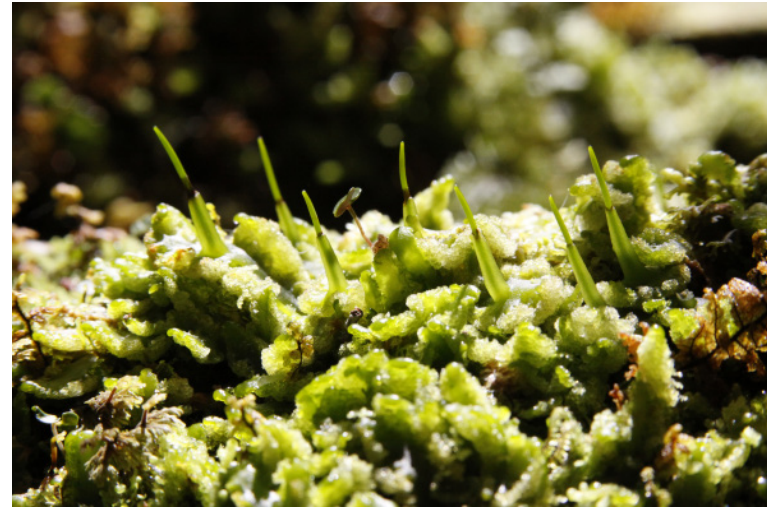

Fig. 26. El antocerote Nothoceros endiviifolius es endémico del sudoeste de Sudamérica. (Fotografía Paola Vezzani).

\section{CONSIDERACIONES}

En este artículo hemos expuesto atributos únicos de la dimensión biofísica de la ecorregión subantártica de Magallanes. El tejido de conexiones biogeográficas explica un aspecto fundamental de las singularidades de la biodiversidad de Cabo de Hornos. Este patrón ha comenzado a ser mejor comprendidas a partir de la invetigacion ecológica y filosófica desarrollado en la $\mathrm{RBCH}$ a comienzos del siglo XXI (Rozzi et al. 2012a). La filosofía ambiental de campo y su actividad específica del ecoturismo con lupa han contribuido a ampliar la comprensión y fortalecer la valoración de esta "joya natural austral", hoy menos ignota pero más requerida de cuidado (Rozzi \& Schüttler, 2015). Los archipiélagos de Cabo de Hornos han representado uno de los pocos grupos insulares del planeta que alcanzaron el siglo XXI libres de impacto humano directo, y representan hoy un refugio natural, a la vez que un laboratorio natural de relevancia planetaria.

Con la aproximación metodológica de la filosofía ambiental de campo que se presenta en este número especial de Magallania procuramos contribuir a asumir la tarea del cuidado del Cabo de Hornos. Chile asume aquí un liderazgo tanto en el monitoreo y estudios ecológicos a largo plazo como en innovadoras formas de valorar y conservar estos archipiélagos y más recientemente el mar de Drake y sus montes submarinos (Rozzi et al. 2017).

La riqueza de relaciones biogeográficas ilustradas en este artículo con un foco en la pequeña flora no-vascular representa sólo uno 
de los dominios de la biodiversidad del Cabo de Hornos; es indispensable fortalecer también programas de ecología microbiana y la exploración de los ecosistemas marinos. Para una valoración y protección de esta singular biota subantártica es necesario, y justo, considerar formas de saber y valores albergados por la cultura de pueblos originarios como el yagán y tradiciones de pensamiento que hoy quedan frecuentemente inadvertidos por la educación, la toma de decisiones y la cultura chilena y global. Para contribuir a suoperar esta omisión, este número especial de Magallania presenta en los artículos siguientes formas de comprender y valorar la biodiversidad del Cabo de Hornos la valoración a través de la metodología de la filosofía ambiental de campo.

\section{AGRADECIMIENTOS}

Agradezco a los numerosos estudiantes e investigadores del Programa de Conservación Biocultural Subantártica coordinado por la Universidad de Magallanes, University of North Texas y el Instituto de Ecología y Biodiversidad de Chile, $y$ en especial a los fotógrafos quienes han permitido ilustrar las afinidades biogeográficas que se observan en la Reserva de la Biosfera Cabo de Hornos. La preparación de este artículo ha contado con el apoyo de los proyectos CONICYT PFB- 23 y Apoyo a Centros Científicos y Tecnológicos de Excelencia con Financiamiento Basal CONICYT AFB170008.

\section{BIBLIOGRAFÍA}

Armesto, J. J., Arroyo, M. K. T., \& C. Villagran. (1980). Altitudinal distribution, cover and size structure of umbelliferous cushion plants in the high Andes of Central Chile. Acta Ecologica, 1, 327-332.

Armesto, J. J., Rozzi, R., Smith-Ramírez, C., \& Arroyo, M. T. K. (1998). Effective conservation targets in South American temperate forests. Science, 282, 12711272.

Arroyo, M. K., Cavieres, L., Peñaloza, A., Riveros, M., \& Faggi, A. M. (1996a). Relaciones fitogeográficas y patrones regionales de riqueza de especies en la flora del bosque lluvioso templado de Sudamérica. In J.J. Armesto, C. Villagrán \& M. K. Arroyo (Eds.), Ecología de los Bosques Nativos de Chile (pp. 71-92). Santiago de Chile: Editorial Universitaria.

Arroyo, M. T. K., Riveros, M., Peñaloza, A., Cavieres, L. A. \& Faggi, A. M. (1996b). Phytogeographic relationships and regional richness patterns of the cool temperate rainforest flora of southern South America. In R. G. Lawford, P. B. Alaback \& E. Fuentes (Eds.), HighLatitude Rainforests and Associated Ecosystems of the West Coasts of the Americas. Climate, Hydrology, Ecology and Conservation (pp. 134-172). New York: Springer.

Bertea L., \& Chevallay, D. (2008). The Spirit of the Southern Wind. El Espíritu del Viento del Sur. Editorial Patagonia Interactiva. Punta Arenas, Chile.

Buck, W. R., \& Goffinet, B. (2010). Preliminary key to the mosses of Isla Navarino, Chile (Prov. Antártica Chilena). Beihefte zur Nova Hedwigia, 138, 215-229.

Couve, E., \& Vidal, C. (2003). Birds of Patagonia, Tierra del Fuego \& Antarctic Peninsula. Punta Arenas: Editorial Fantástico Sur Birding Ltda.

Donoghue, M. J. (2011). Bipolar biogeography. Proceedings of the National Academy of Sciences, 108, 63416342.

Goffinet, B., Rozzi, R., Lewis, L., Buck, W., \& Massardo, F. (2012). The Miniature Forests of Cape Horn: Eco-Tourism with a Hand-lens ("Los Bosques en Miniatura del Cabo de Hornos: Ecoturismo con Lupa”). Bilingual English-Spanish edition. Denton TX \& Punta Arenas: UNT Press - Ediciones Universidad de Magallanes

Jiménez, J. E., Jahn, A. E., Rozzi, R., \& Seavy, N. E. (2016). First documented migration of individual White-crested Elaenias (Elaenia albiceps chilensis) in South America. The Wilson Journal of Ornithology, 28(2), 419-425

Lewis L. R, Rozzi, R., \& Goffinet, B. (2014a). Direct longdistance dispersal shapes a New World amphitropical disjunction in the dispersal-limited dung moss Tetraplodon (Bryopsida: Splachnaceae). Journal of Biogeography, 41(12), 2385-2395.

Lewis. L. R., Behling, E., Gousse, H., Qian, E., Elphick1, C. S., Lamarre, J. F, Bêty, J.,... \& Goffinet, B. (2014b). First evidence of bryophyte diaspores in the plumage of transequatorial migrant birds. PeerJ, 2, e424

Li, H. M., \& Zhou, Z. K. (2007). Fossil nothofagaceous leaves from the Eocene of western Antarctica and their bearing on the origin, dispersal and systematics of Nothofagus. Science in China, 50(10), 1525-1535.

Martinic, M. (2005). Crónica de las tierras al sur del canal Beagle. Punta Arenas: Ediciones Hotel Lakutaia

Marticorena, A., Alarcón, D., Abello, L., \& Atala, C. (2010). 
Plantas trepadoras, epífitas y parásitas nativas de Chile. Guía de Campo. Concepción: Ed. Corporación Chilena de la Madera.

Méndez, M., Rozzi, R., \& Cavieres, L. (2013). Flora vascular y no-vascular en la zona altoandina de la isla Navarino (55oS), Reserva de Biosfera Cabo de Hornos, Chile. Gayana Botánica, 70(2), 337-343.

Mittermeier, R. A., Mittermeier, C., Robles-Gil, P., Pilgrim, J., Fonseca, G., Brook, T., \& Konstant, W. (2002). Wilderness: Earth's last wild places.Washington, D.C: CEMEX-Conservation International.

Mittermeier, R. A., Mittermeier, C. G., Brooks, T. M., Pilgrim, J. D., Konstant, W. R., Da Fonseca, G. A. B., \& Kormos, C. (2003). Wilderness and biodiversity conservation. Proceedings of the National Academy of Sciences, 100, 10309-10313.

Moore, D. M. (1983). Flora of Tierra del Fuego. Shrewsbury: Livesey Limited.

Muñoz, J., Felicísimo, A. M., Cabezas, F., Burgaz, A. R., \& Martínez, I. (2004). Wind as a long-distance dispersal vehicle in the southern hemisphere. Science, 304, 1144-1147.

Ocampo, C., \& Rivas, P. (2000). Nuevos fechados 14C de la costa norte de la isla Navarino, costa sur del canal Beagle, Provincia Antártica Chilena, región de Magallanes. Anales del Instituto de la Patagonia, 28, 23-35.

Pisano. E. (1972). Observaciones Fito-Ecológicas en las islas Diego Ramírez. Anales Instituto Patagonia, 3, 161169.

Pisano, E. (1977). Fitogeografía de Fuego-Patagonia chilena I. Comunidades vegetales entre las latitudes $52^{\circ}$ y $56^{\circ} \mathrm{S}$. Anales del Instituto de la Patagonia, Serie Ciencias Naturales, 8, 121-250.

Popp, M., Mirré, V., \& Brochmann, C. (2011). A single MidPleistocene long-distance dispersal by a bird can explain the extreme bipolar disjunction in crowberries (Empetrum). PNAS, 108, 6520-6525.

Rivas, P., Ocampo, C., \& Aspillaga, E. (1999). Poblamiento temprano de los Canales Patagónicos: el núcleo septentrional. Anales del Instituto de la Patagonia, 27, 221-230.

Rozzi, R. (2002). Biological and Cultural Conservation in the Archipelago Forest Ecosystems of Southern Chile. Ph.D. Dissertation, Department of Ecology and Evolutionary Biology, University of Connecticut, USA.

Rozzi, R. (2012). Serendipity in the origin of ecotourism with a hand lens (Serendipia en el origen del ecoturismo con lupa). In B. Goffinet, R. Rozzi, L. Lewis, W. Buck \& F. Massardo (Eds.), The Miniature Forests of Cape Horn: Eco-Tourism with a Hand-lens ("Los Bosques en Miniatura del Cabo de Hornos: Ecoturismo con Lupa") (pp. 11-26) Bilingual English-Spanish edition. Denton TX and Punta Arenas: UNT Press-Ediciones Universidad de Magallanes.

Rozzi, R., \& Jiménez, J. E. (Eds). (2014). Magellanic Subantarctic Ornithology: First Decade of Forest Bird Studies at the Omora Ethnobotanical Park, Cape Horn Biosphere Reserve. Denton TX, USA Punta Arenas: UNT Press - Ediciones Universidad de Magallanes.

Rozzi, R., \& Schüttler, E. (2015). Primera década de investigación y educación en la Reserva de la Biosfera Cabo de Hornos: el enfoque biocultural del Parque Etnobotánico Omora. Anales del Instituto de la Patagonia, 43(2), 75-99.

Rozzi, R., Massardo, F., Anderson, C., Heidinger, K., \& Silander Jr, J. (2006a). Ten principles for biocultural conservation at the southern tip of the Americas: the approach of the Omora Ethnobotanical Park. Ecology \& Society, 11(1), 43.

Rozzi, R., Massardo, F., Berghoefer, A., Anderson, C., Mansilla, A., Mansilla, M., Plana, J.,... \& Araya, P.. (2006b). The Cape Horn Biosphere Reserve. Punta Arenas: Ediciones Universidad de Magallanes.

Rozzi, R., Massardo, F., Mansilla, A., Anderson, C. B., Berghöfer, A., Mansilla, M., Gallardo M. R.,... \& Barros, E. (2007). La reserva de biosfera Cabo de Hornos: un desafío para la conservación de la biodiversidad e implementación del desarrollo sustentable en el extremo austral de América. Anales del Instituto de la Patagonia, 35, 55-70.

Rozzi, R., Armesto, J., Goffinet, B., Buck, W., Massardo, F., Silander, J., Kalin-Arroyo, M.,... \& Callicott, J. B. (2008). Changing lenses to assess biodiversity: patterns of species richness in sub-Antarctic plants and implications for global conservation. Frontiers in Ecology and the Environment, 6, 131-137.

Rozzi, R., Armesto, J. J., Gutiérrez, J., Massardo, F., Likens, G., Anderson, C. B., Poole, A.,... \& Kalin, M. T.. (2012a). Integrating ecology and environmental ethics: Earth stewardship in the southern end of the Americas. BioScience, 62(3), 226-236.

Rozzi, R., Lewis, L., Massardo, F., Medina, Y., Moses, K., Méndez, M., Sancho, L.,... \& Goffinet, B. (2012b). Ecotourism with a Hand-Lens at Omora Park. It includes the documentary "The Invisible Journey" by 
Jaime Sepúlveda, and photography by Adam Wilson. Punta Arenas: Ediciones Universidad de Magallanes.

Rozzi, R., Massardo, F., Mansilla, A., Squeo, F. A., Barros, E., et al. (2017). Parque Marino Cabo de Hornos Diego Ramírez. Informe Técnico para la Propuesta de Creación. Programa de Conservación Biocultural Subantártica. Punta Arenas: Ediciones Universidad de Magallanes.

Schmithüsen, J. (1956). Die räumliche Ordnung der chilenischen Vegetation. Bonner Geographische Abhandlungen, 17, 1-86.

Tuhkanen, S., Kuokka, I., Hyvönen, J., Stenroos, S., \& Niemela, J. (1990). Tierra del Fuego as a target for biogeographical research in the past and present. Anales del Instituto de la Patagonia, Serie Ciencias Naturales, 19(2), 5-107.

Veblen, T. T., Hill, R. S. \& Read, J. (Eds.) (1996). The Ecology and Biogeography of Nothofagus Forests. New Haven: Yale University Press.

Villagrán, C. (2018). Biogeografía de los bosques subtropical- templados del sur de Sudamérica. hipótesis históricas. Magallania (en este volumen).

Villagrán, C., \& Armesto, J. J. (2005). Fitogeografía histórica de la Cordillera de la Costa de Chile. En C. SmithRamírez, J.J. Armesto \& C. Valdovinos (Eds.), Historia, Biodiversidad y Ecología de los bosques de la Cordillera de la Costa de Chile. Santiago de Chile: Editorial Universitaria

Villagrán, C., \& Hinojosa, L. F. (1997). Historia de los bosques del sur de Sudamérica, II: Análisis fitogeográfico. Revista Chilena de Historia Natural, 70, 241-267.

Villagrán, C., \& Hinojosa, L. F. (2005). Esquema Biogeográfico de Chile. En J. Llorente \& J. J Morrone (Eds.), Regionalización Biogeográfica en Iberoámeríca y tópicos afines. Capitulo 33 (pp. 551-577). Ciudad de México: Ediciones de la Universidad Nacional Autónoma de México.

Villagrán, C., Hazle, G., \& Barrera, E. (2005). Hepáticas y antocerotes del archipiélago de Chilé. Santiago de Chile: Museo Nacional de Historia Natural. 
